\title{
Comparison of Advanced Troposphere Models for Aiding Reduction of PPP Convergence Time in Australia
}

\author{
Deo M., El-Mowafy A. \\ School of Earth and Planetary Sciences, Curtin University \\ Journal of Spatial Sciences, 2018, https://doi.org/10.1080/14498596.2018.1472046
}

\begin{abstract}
This paper firstly analyses the precision of tropospheric zenith total delay (ZTD) values obtained from the empirical models GPT2 and GPT2w, and the numerical weather models (NWM) from Australian Bureau of Meteorology (BoM), and European Centre for Medium-Range Weather Forecasts (ECMWF). Comparison of these ZTD values with IGS ZTD product at four sites showed that the ZTDs from NWM datasets were more precise than the empirical models. The ZTD from BoM data gave the best results, with mean errors between $-0.034 \mathrm{~m}$ to $0.029 \mathrm{~m}$ and standard deviations better than $0.045 \mathrm{~m}$.
\end{abstract}

Next, the PPP convergence time and achievable accuracy using the BoM NWM constrained ZTD by including them as pseudo-observations with a pre-set precision was compared to the case of estimating the troposphere. This resulted in a slight enhancement in convergence time, and improvements in vertical positioning accuracy was found at all the four tested sites at $0.036-0.058 \mathrm{~m}$ after 2 minutes, $0.023-0.038 \mathrm{~m}$ after 3 minutes and $0.013-0.020 \mathrm{~m}$ after 5 minutes of PPP initialisation.

Keywords: precise point positioning, troposphere constraint, numerical weather models, convergence, GNSS

\section{Introduction}

The troposphere is that part of the atmosphere between the Earth's surface up to an altitude of approximately 20-60km (El-Mowafy and Lo, 2014). It delays GNSS signals travelling through the same path equally, irrespective of their frequencies, and is thus usually referred to as the neutral atmosphere. The magnitude of total tropospheric delay depends on the signal path through the neutral atmosphere. It is typically lowest in the zenith direction and increases as the satellite elevation angle is reduced. It consists of a hydrostatic or dry component, which can be modelled accurately to an accuracy of $98 \%$ with an empirical model such as the Saastamoinen (Saastamoinen 1973) model, and a wet component which is more difficult to model precisely due to the temporal changes in water vapour pressure along the troposphere layer. The standard PPP model considers the troposphere to be isometric and estimates either the zenith total delay (ZTD), or computes the zenith hydrostatic delay (ZHD) with an empirical model and estimates the zenith wet delay (ZWD) as a parameter. Mapping functions, such as the Vienna Mapping Function (VMF), are then used to calculate the tropospheric delay at the observed satellite elevation angle, as discussed in Tuka and ElMowafy (2013) where several mapping functions were compared. However, the ZWD is highly correlated with the height parameter (Kjørsvik et al., 2006) and it requires a significant change in satellite geometry and longer observation time to reliably separate the correlation between these parameters. The commonly used random walk or first-order Gauss-Markov autocorrelation models often underestimate the temporal correlations in the ZWD, thus more complex dynamic models are required to depict the water vapour variability (El-Mowafy and Lo, 2014). Ultimately, the troposphere is a nuisance parameter in PPP and if it is known 
apriori from an external model with inherent accuracy, appropriate constraints may be applied to improve the PPP model. This may result in a reduction in convergence time or improve the achieved accuracy, which is a key problem in PPP.

Several researchers have considered constraining the troposphere error by using empirical models or external data. Kjørsvik et al. (2006) compared PPP performance for the UNB3 empirical tropospheric model developed by Collins and Langley (1996) with the traditional model that estimated the tropospheric error as a parameter. The nominal accuracy of the apriori ZWD model from UNB3 model was $0.035 \mathrm{~m}$ and when depending on this only, the study showed that horizontal accuracy of sub- $0.2 \mathrm{~m}$ can be achieved. The vertical accuracy was much worse, which did not improve with longer observation periods. Shi et al. (2014) computed the precise tropospheric corrections generated from a local area network of GNSS receivers, which are next transmitted to users as a second order polynomial function to improve PPP performance. Thus, users get improved PPP accuracy and convergence time when located within the GNSS network coverage area that is used to determine tropospheric corrections. The Trimble RTX service with tropospheric correction models the ZTD from a network of GNSS stations and reported providing sub- $0.05 \mathrm{~m}$ level horizontal PPP accuracy within a few minutes (Talbot et al., 2015). Laurichesse and Privat (2015) used welldetermined troposphere and ionosphere information from regional augmentation to reduce PPP convergence time to within minutes.

Zhang et al. (2016) compared three tropospheric models - IGGtrop, EGNOS and UNB3m for PPP within China. The IGGtrop, which had an RMS error of $0.044 \mathrm{~m}$ compared to precise IGS final ZTD products, gave the best positioning accuracy in the vertical component with a mean positioning error of $0.15 \mathrm{~m}$. The EGNOS and UNB3m models gave slightly worse mean vertical errors of $0.21 \mathrm{~m}$ and $0.19 \mathrm{~m}$ respectively. However, the IGGtropo, a 3-dimensional grid based model, has been developed to provide tropospheric delay for the users of Chinese Beidou Navigation Satellite System and the area augmentation system based on BDS in China (Zhang et al., 2016). It uses a 3D grid to calculate ZTD to obtain more homogenous performances for different areas of China, hence giving superior performance in the BDS coverage area. It may also be applied on a global scale with a mean bias of $-0.8 \mathrm{~cm}$ and RMS of $4.0 \mathrm{~cm}$, which is comparable to the EGNOS and UNB3m models (Li et al., 2012).

Other empirical troposphere models that may be used in PPP include European Space Agency GAL-TROPO (Martellucci 2012), TropGrid (Kruegger et al., 2004) and its update TopGrid2 (Schüler, 2014). Zheng et al. (2017) developed a new troposphere correction model based on GPT2w to reduce PPP convergence time. The RMS of the ZTD with this model was $1.2 \mathrm{~cm}$, compared to $3.6 \mathrm{~cm}$ for GPT $2 \mathrm{w}$. The improvement was due to a modified parameter of the ZWD exponential delay with respect to height. When the new model was applied to PPP, the convergence time reduced significantly by $20-50 \%$ for Beidou only PPP, due to the significant improvement in geometry for this constellation. Zhou et al. (2017) developed two site specific troposphere models based on the Saastamoinen and Callaham models using radiosonde data from 2005 to 2012. The Saastamoinen based model had the best performance with a mean bias of $0.19 \mathrm{~cm}$ and RMS of $3.19 \mathrm{~cm}$. The study also showed that troposphere models based on actual data perform better when recent meteorological data is used to build the model. This implies that tropospheric models require regular updates to remain valid. Lu et al. (2017) used multi-constellation GNSS data from the IGS Multi-GNSS Experiment (MGEX) network of 30 global stations to retrieve a real-time troposphere model using the PPP technique. The ZTD estimates from the GFZC2 IGS real-time service gave the best accuracy of $5.06 \mathrm{~mm}$. With multi-constellation GNSS data, the accuracy of the real-time ZTD 
improved further by up to $22.2 \%$, compared to the GPS only case. Vaclavovic et al. (2017) developed an augmented troposphere model for real-time kinematic PPP, using Numerical Weather Model (NWM) data which reflected the actual state of the atmosphere. When the ZTD was estimated as a parameter, the study found considerable correlation between the rover height and the ZTD, as also reported in Kjørsvik et al. (2006). When using the external tropospheric model, the PPP solution improved by shortened convergence time, better robustness in the case of degraded satellite geometry, and less parameters with lower correlation. The height accuracy of the PPP solution in kinematic model was $9-12 \mathrm{~cm}$ when using external troposphere model. Lu et al. (2016) developed a NWM constrained PPP model to improve the performance of multi-constellation GNSS PPP. The troposphere delay parameter from the European Centre for Medium-Range Weather Forecasts (ECMWF) was used in a four constellation (GPS, GLONASS, Beidou and Galileo) PPP model. The standard PPP results were compared to the NWM constrained results. In standard PPP, the tropospheric ZHD delay was corrected using GPT2, whereas ZWD was estimated as an unknown parameter along with receiver position, receiver clock, two horizontal tropospheric gradients (north-south and east-west components), ionosphere delays, code biases and carrier phase ambiguities. In the NWM constrained PPP, the ZWD from ECMWF was used as an apriori value, but a residual wet delay parameter was estimated to account for the imperfections in the ZWD derived from the NWM. Thus, the ZWD and two horizontal tropospheric gradients in the standard PPP model were replaced by a single residual wet delay parameter, hence reducing the number of unknown parameters by two. The improvements in convergence time in the NWM constrained PPP model was 20\%, 32\% and $25 \%$ in the north, east and vertical components, whereas positioning accuracy improved by $2.5 \%, 12.1 \%$ and $18.7 \%$ in the same components.

In this contribution, we study the feasibility of applying tropospheric models from four different sources to constrain the tropospheric ZTD parameter. These are the empirical models GPT2 and its revision GPT2w, the NWM from ECMWF gridded data product, and for the first time the Australian Bureau of Meteorology (BoM) GRIB version 2 data. The use of atmospheric profiles from radio occultation data from COSMIC/ FORMOSAT-3 satellites was also considered, but this was not found to be feasible at present due to the limited number of satellites. This analysis was conducted for a period of one year. We next compare the performance of using the BoM model to constraint the troposphere error, which gave the best precision out of the four tested models, in terms of PPP convergence time and achievable accuracy, to the traditional case where the troposphere is estimated as an unknown parameter. We apply appropriate weighting to the troposphere correction model as determined from the long term analysis to the constraint equations. While other researchers (e.g. Kjørsvik et al., 2006) have attempted constraining the troposphere with a dual-frequency model in PPP, our study focuses on use of triple frequency data from multi-constellation GNSS. The availability of triple frequency civil signals is a feature of the major GNSS constellations such as GPS, Galileo, and Beidou. Therefore, we study the attainment of sub-decimetre PPP accuracy with multi-constellation and multi-frequency GNSS data with advanced NWM data from BoM to constrain the troposphere.

The next section briefly describes each of the tropospheric models that were studied, their data sources, and application. Next, we evaluate their accuracy by comparing them to the IGS final ZTD values at selected Australian sites over a one-year period. Finally, we analyse the impact of applying the BoM NWM constrained troposphere on PPP convergence time and accuracy. 


\section{PPP Functional Model}

This section presents the PPP functional model for estimating the ZTD as a parameter, followed by constraining it by using external information. In this study, the triple frequency PPP model with code-only and phase-only triple frequency ionosphere free code and phase combinations was used with simulated multi-constellation GNSS data from GPS, Beidou and Galileo constellations. The phase- and code-only ionosphere free, geometry preserving and least noise propagation linear combination was used in the PPP model, which leads to improved convergence performance (Deo and El-Mowafy, 2016). This combination is expressed as:

$$
\begin{aligned}
& P(I F)=\alpha_{1} P 1+\alpha_{2} P 2+\alpha_{3} P 3 \\
& \phi(I F)=\alpha_{1} \phi 1+\alpha_{2} \phi 2+\alpha_{3} \phi 3
\end{aligned}
$$

where $P(I F), \phi(I F)$ are the triple frequency code and phase linear combinations, $P 1, \mathrm{P} 2, \mathrm{P} 3$ and $\phi 1, \phi 2, \phi 3$ are the code and phase measurements on individual frequencies (e.g. L1, L2 and L5 for GPS) and $\alpha_{1}, \alpha_{2}, \alpha_{3}$ are the linear combinations coefficients.

\subsection{Estimating the Troposphere as a parameter}

The equations for the functional models for GPS, Beidou and Galileo are given below, after application of satellite clock correction and differential hardware biases. In this model, the ZHD is computed with an empirical model and the ZWD is estimated as a parameter in the vertical component which is projected along the receiver-to-satellite line of sight using a wet mapping function $\left(m_{w}\right)$.

For example, using the GPS constellation, denoted as $\mathrm{G}$ we have:

$$
\begin{gathered}
P(I F)^{G}=\alpha_{1, G} P_{L 1}^{G}+\alpha_{2, G} P_{L 2}^{G}+\alpha_{3, G} P_{L 5}^{G}=\rho^{G}+c d t_{\mathrm{G}}+m_{w}^{G} Z W D+\varepsilon_{\mathrm{P}}^{\mathrm{G}} \\
\phi(I F)^{G}=\alpha_{1, G} \phi_{L 1}^{G}+\alpha_{2, G} \phi_{L 2}^{G}+\alpha_{3, G} \phi_{L 5}^{G}=\rho^{G}+c d t_{\mathrm{G}}+\lambda_{G} N^{*} G+m_{w}^{G} Z W D+\varepsilon_{\phi}^{G}
\end{gathered}
$$

where $G$ is a GPS satellite, $\rho^{G}$ is the satellite-to-receiver geometric range, $c$ is the speed of light in vacuum; $d t_{\mathrm{G}}$ is the receiver clock offset; $N^{*} G$ is the non-integer phase ambiguity; $\varepsilon_{P i}^{\mathrm{G}}$ and $\varepsilon_{\phi_{i}}^{G}$ comprises code and phase measurement combined noise and multipath, respectively. The best coefficient values estimated for the above combination are : $\alpha_{1, G}=2.326944$, $\alpha_{2, G}=-0.359646$, and $\alpha_{3, G}=-0.967299$ (Li et al. 2014; Deo and El-Mowafy 2016).

For the Beidou constellation (denoted as $C$ ) the observation equations are:

$$
\begin{gathered}
P^{C}=\alpha_{1, C} P_{B 1}^{C}+\alpha_{2, C} P_{B 2}^{C}+\alpha_{3, C} P_{B 3}^{C}=\rho^{C}+c d t_{G}+I S B_{G-C}+m_{w}^{C} Z W D+\varepsilon_{P_{j}}^{C} \\
\phi^{C}=\alpha_{1, C} \phi_{B 1}^{C}+\alpha_{2, C} \phi_{B 2}^{C}+\alpha_{3, C} \phi_{B 3}^{C}=\rho^{C}+c d t_{G}+I S B_{G-C}+\lambda_{C} N^{* C}+m_{w}^{C} Z W D+\varepsilon_{\phi}^{C}(6)
\end{gathered}
$$

The terms are similar to the ones described for system $G$ above, with the addition of $I S T B_{G-C}$, which is the inter-system time bias between GPS and Beidou, combined for the receiver and the satellite. For Beidou, the coefficient values are found to be: $\alpha_{1, c}=$ $2.566439, \alpha_{2, C}=-1.228930$, and $\alpha_{3, C}=-0.337510$.

Similar ionosphere-free equations are derived for the Galileo constellation (denoted as $E$ ) such that :

$$
\begin{gathered}
P^{E}=\alpha_{1, E} P_{E 1}^{E}+\alpha_{2, E} P_{E 5 a}^{E}+\alpha_{3, E} P_{E 5 b}^{E}=\rho^{E}+c d t_{G}+I S B_{G-E}+m_{w}^{E} Z W D+\varepsilon_{P}^{E} \\
\phi^{E}=\alpha_{1, E} \phi_{E 1}^{E}+\alpha_{2, E} \phi_{E 5 a}^{E}+\alpha_{3, E} \phi_{E 5 b}^{E}=\rho^{E}+c d t_{G}+I S B_{G-C}+\lambda_{E} N^{* E}+m_{w}^{E} Z W D+\varepsilon_{\phi}^{E}
\end{gathered}
$$

with coefficients $\alpha_{1, E}=2.314925, \alpha_{2, E}=-0.836269$, and $\alpha_{3, E}=-0.478656$. 
If we consider the case of a GNSS receiver tracking 1 to $n$ GPS satellites, 1 to $m$ Beidou satellites, and 1 to $k$ Galileo satellites at an instant of time, the unknown parameters for a float PPP approach would be:

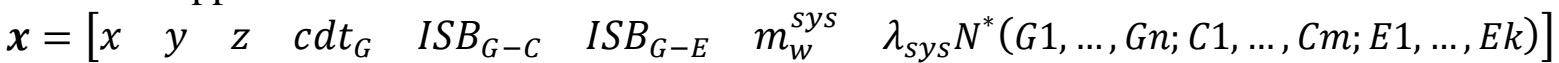

where $x, y, z$ denotes the unknown receiver position. The functional and stochastic models of the above combinations are discussed in (Deo and El-Mowafy 2016).

\subsection{A Modified PPP Model Constraining the Troposphere}

In this section, constraining of the ZTD obtained from external sources as additional 'quasi' observations in the PPP model is discussed. These ZTD values are estimated with associated uncertainties, for instance standard deviations. At the receiver, instead of treating the modelled ZTD as known values in the observation equations, they are added as 'quasi' observations with their uncertainty (precision). Thus, the observation vector of the code and phase observations and their covariance matrices (denoted as $Q_{P}$ and $Q_{\phi}$ ) are augmented to include an additional 'quasi' observation $\tilde{T}$ to constraint the vertical troposphere, which is computed from the troposphere models. The observation equation of this quasi-observation is expressed as:

$$
\tilde{T}=T+\varepsilon_{\tilde{T}}
$$

$\varepsilon_{\tilde{T}}$ is the noise in $\tilde{T}$. Using GPS as an example, the linearized fault-free measurement model using all satellites in view is given as:

$$
y=H x+\varepsilon
$$

where $y$ and $x$ are the vectors of observations and unknowns, respectively, $H$ is the design matrix and $\varepsilon$ denotes the noise. Combining the observation Equations (3), (4) and (11), the final system of observation equations for $n$ GPS satellites as an example is expressed as:

$$
\underbrace{\left(\begin{array}{c}
P(I F)^{G} \\
\phi(I F)^{G} \\
\tilde{T}
\end{array}\right)}_{y}=\underbrace{\left(\begin{array}{cccc}
G & u & m_{w}^{G} & 0 \\
G & u & m_{w}^{G} & \lambda_{G} \times I \\
0 & 0 & 1 & 0
\end{array}\right)}_{H} \underbrace{\left(\begin{array}{c}
X_{u} \\
c \overline{d t}(I F)_{G} \\
T \\
N^{* G}(I F)
\end{array}\right)}_{x}+\varepsilon \quad \text { for } s=1 \text { to } n
$$

The design matrix $H$ is full rank, where $G$ is the geometry (direction-cosine) matrix computed from precise ephemeris with dimension $n \times 3, I$ is the identity matrix of dimension $n, u$ is a unit vector of ones and $m_{w}^{G}$ is a column vector representing the line-of-sight troposphere mapping function. The observation covariance matrix is expressed as $Q_{y}=\operatorname{diag}\left(Q_{P(I F)^{G}}\right.$, $\left.Q_{\phi(I F)^{G}}, Q_{\tilde{T}}\right)$, for $s=1$ to $n$. The sub-covariance matrices $Q_{P(I F)^{G}}$ and $Q_{\phi(I F)^{G}}$ are typically assumed diagonal for the observed satellites, with a priori values as shown in El-Mowafy (2015) weighted using an arbitrary satellite elevation-angle dependent model, and uncorrelated code and phase observations. $Q_{\tilde{T}}$ is uncorrelated with $Q_{P(I F)^{G}}$ and $Q_{\phi(I F)^{G}}$, and is assumed diagonal with the standard deviation of the quasi-observation $\left(\sigma_{\tilde{T}}\right)$ either assumed or estimated from external source. 


\section{Troposphere Modelling}

The tropospheric delay, $T$, along a GNSS satellite elevation angle, $E$, is modelled as (Böhm et al., 2006a):

$$
T(E)=m_{h} Z H D+m_{w} Z W D
$$

where $Z H D, Z W D$ are the hydrostatic and wet delay components in zenith direction, and $m_{h}$, $m_{w}$ are the hydrostatic and wet mapping functions, respectively. The zenith hydrostatic delay (ZHD) can be adequately calculated with the empirical models such as the Saastamoinen's formula Saastamoinen (1972), given in Davis et al (1985) as:

$$
Z H D=P \times \frac{0.0022768}{1-0.00266 \cos (2 \phi)-0.28 \times 10^{-6} h}
$$

where $P$ is the surface atmospheric pressure in $\mathrm{hPa}, \phi$ is the station latitude in radians, and $h$ is the station orthometric or ellipsoid height in metres. The difference due to using either height system is negligible (IERS Conventions, 2010). The pressure can be computed from an empirical model, a numerical weather model (NWM) or with in-situ measurements at the observing location.

The zenith wet delay (ZWD) can be approximately calculated if measurements of relative humidity $(R H)$ and temperature are available at the observing station, for instance expressed as (Andrei and Chen, 2009):

$$
Z W D=0.002277\left(\frac{1255}{t}+0.05\right) e
$$

where $t$ is the temperature in Kelvin and $e$ is the partial water vapour pressure, which can be calculated from the $R H$ measurements as

$$
e=6.108 \frac{R H}{100} \cdot e^{\left(\frac{17.15 t-4684}{t-38.45}\right)}
$$

Hence, the surface temperature and either the relative humidity or partial water vapour pressure measurements are required to calculate approximate ZWD. However, an accurate estimation of ZWD would require knowing the water vapour content along the whole length of the troposphere layer, using for instance water vapour radiometers. Since these expensive instruments are not available for normal users, the ZWD parameter is usually estimated as an unknown parameter in the standard PPP model, whereas the ZHD component is modelled with Eq. 14 with a hydrostatic mapping function.

The next sections describe some of the options for modelling the troposphere delay using empirical models and NWMs.

\subsection{GPT Model and its revisions}

The Global Pressure Temperature (GPT) empirical model (Böhm, et al., 2007) and its revisions GPT2 (Lagler et al., 2013) followed by GPT2w (Böhm et al., 2015) may be used to determine the required parameters for calculating the troposphere delay. Although GPT enables calculation of the pressure value in Eq. 14, it is inadequate for precise positioning applications where precise heights are required. Kouba (2009) reported height errors in the standard PPP solution of $0.10 \mathrm{~m}$ or more when satellites below $10^{\circ}$ are included and only the ZHD is modelled. GPT2 was introduced as a refinement of GPT, which enables calculation of pressure, temperature, temperature lapse rate, partial water vapour, as well as the hydrostatic and wet coefficients, defined as $a_{h}$ and $a_{w}$, that are required by the Vienna Mapping Function (VMF1) (Böhm et al., 2006a). This enables users to apply the more precise VMF1, compared to other functions such as the Global Mapping Function (GMF) (Böhm et al., 2006b). Application of VMF1 requires use of the coefficients $a_{h}$ and $a_{w}$ for 
calculating $m_{h}$ and $m_{w}$, respectively, which are subsequently used to calculate $Z W D$ and $Z H D$ values using Eq. 13 .

The GPT2w model is an extension of GPT2, with improved capability to determine the ZWD empirically (Böhm et al., 2015). This was validated with the zenith total delay (ZTD = $Z H D+Z W D$ ) estimates from the IGS precise ZTD products at 341 GNSS sites over 110 days (Böhm et al., 2015). The difference between the GPT2w derived ZTD and the IGS determined delays ranged between $-0.042 \mathrm{~m}$ and $+0.073 \mathrm{~m}$, with a mean difference of $0.0002 \mathrm{~m}$ and RMS of $0.036 \mathrm{~m}$. The GPT $2 \mathrm{w}$ requires gridded raw data with regular intervals of either $5^{0}$ or the higher $1^{0}$ resolution, along with the station location, height and date as input parameters. The model interpolates the pressure, temperature, temperature lapse rate, mean temperature of water vapour, water vapour pressure, water vapour lapse rate, geoid undulation and the coefficients for the hydrostatic and wet mapping functions for a given location and date. The ZHD can be calculated using Eq. 14 whereas the ZWD is expressed as (Askne and Nordius, 1987):

$$
Z W D=10^{-6}\left(k_{2}^{\prime}+k_{3} / t_{m}\right) \frac{R_{d}}{(\lambda+1) g} e_{s}
$$

where $k_{2}^{\prime}$ and $k_{3}$ are empirically determined coefficients, $R_{d}$ denotes the specific gas constant for the dry constituents and $g$ is the gravity constant. The variable $e_{s}$ is the water vapour pressure at the site, $\lambda$ is the water vapour lapse rate, $t_{m}$ is the mean temperature of the water vapour in degrees Kelvin. All these values can be computed from the GPT2w model (Böhm et al., 2015). The hydrostatic and wet mapping functions are calculated with VMF1 using the respective coefficients, $a_{h}$ and $a_{w}$, and the total tropospheric delay is finally calculated by using Eq. 13.

\subsection{Numerical Weather Models}

To achieve mm accuracy in station height, ZHD must be known to better than $0.01 \mathrm{~m}$ accuracy. This requires pressure values with better than $5 \mathrm{hPa}$ accuracy from in-situ measurements at the station, or NWM data (Kouba, 2009). Such accuracy is achievable from the Global Data Assimilation System (GDAS), produced at $1^{0} \times 1^{0}$ grid in real time by the National Center for Environment Prediction (NCEP) of the US National Oceanic and Atmospheric Administration (NOAA). The ZWD may also be modelled using relative humidity or partial water pressure values from NWMs. Andrei and Chen (2009) used GDAS data for computing both the hydrostatic and wet zenith delay, which agreed to IGS total zenith delay to within $0.05 \mathrm{~m}$. In their study, the agreement between GDAS meteorological values and in-situ direct measurements at selected IGS stations was 1 mbar in pressure, 3 degrees Celsius for temperature and $13 \%$ for relative humidity. Most of the error was attributed to the poor quality of relative humidity and temperate values from GDAS, which resulted in less accurate estimation of ZWD.

Although NWMs can provide $0.05 \mathrm{~m}$ level ZTD estimates, their implementation requires additional time and resources by the users to acquire data from external sources. An advantage of this approach is that it can be adopted for real-time PPP, even when there is data outage since the weather models forecast data for several hours into the future. The next subsections describe two NWMs that have been used in this study. 


\subsubsection{ECMWF}

The European Centre for Medium-Range Weather Forecasts (ECMWF) produces coefficients for calculation of ZWD and ZHD on a global grid of $2.0^{\circ}$ interval in north-south and $2.5^{\circ}$ in east-west. These coefficients are produced every 6 hours at 00, 06, 12 and 18 UTC at http://ggosatm.hg.tuwien.ac.at. This website also provides the ZHD and ZWD values in metres, in these grid and time intervals. The ZHD and ZWD values are for ellipsoidal heights $\left(h_{D E M}\right)$, which is obtained from a digital elevation model (DEM), for instance available from the website http://ggosatm.hg.tuwien.ac.at/DELAY/GRID/orography ell, with a grid resolution of $2.0^{\circ}$ for latitude and $2.5^{\circ}$ for longitude. The interpolation of $a_{h}, a_{w}, Z H D, Z W D$ and $h_{D E M}$ at the required station latitude and longitude $(\phi, \lambda)$ is performed using a bilinear model.

Provided that the difference between $h_{D E M}$ and the station height $h$ is within $1 \mathrm{~km}$, the ZHD at the station, $Z H D_{h}$, can be extrapolated using the formula (Steigenberger et al., 2009):

$$
Z H D_{h}=Z H D_{h_{D E M}}-2.77 \times 10^{-3} \frac{g \cdot P\left(h_{D E M}\right)}{R \cdot t\left(h_{D E M}\right)}\left(h-h_{D E M}\right)
$$

where $R=8.3144621 \mathrm{~J} \cdot \mathrm{K}^{-1} \cdot \mathrm{mol}^{-1}$ is the molar gas constant and the height difference is in $\mathrm{km}$ units. The pressure $P\left(h_{D E M}\right)$ and temperature $t\left(h_{D E M}\right)$ at the station with the $h_{D E M}$ estimated at its location may be computed with the use of GPT2w model.

\subsubsection{Australian Bureau of Meteorology ACCESS data}

The Australian Community Climate and Earth-System Simulator (ACCESS) data is available from the Australian Bureau of Meteorology (BoM) as gridded binary (GRIB) edition 2 as well as Network Common Data Form-4 (NetCDF-4) formats. Further details of the different types of products and their accessibility is available at http://reg.bom.gov.au/nwp/doc/access/NWPData.shtml. The ACCESS-Regional (R) data contains meteorological data on three-dimensional grids in the greater Australian region, at a resolution of $12 \mathrm{~km}$. There are various versions of the data files, containing different combinations of parameters which may be deduced from the filenames.

In this study, the ACCESS-R single level surface data was used. This product is released every six hours at UTC base hours 00, 06, 12 and 18, and for each base time, there are three files issued with forecast validity times of 3, 6 and 9 hours. This data was converted to netCDF-4 using the wgrib2 software (www.cpc.ncep.noaa.gov/products/wesley/wgrib2/) and decoded using an in-house software. The key useful fields in this file include the surface temperature in Kelvin, surface pressure in $\mathrm{Pa}$ and the relative humidity at $1.5 \mathrm{~m}$ above ground. Hence, the ZWD can be calculated using Eqs. 15 and 16, and ZHD with Eq. 14, once the relative humidity, temperature and pressure values are interpolated at a given station location and time.

\subsection{Radio Occultation from COSMIC satellites}

The Constellation Observing System for Meteorology, Ionosphere and Climate (COSMIC) / Formosa Satellite 3 (FORMOSAT-3) constellation of six satellites were launched into a low-Earth orbit (LEO) in April 2006. Since then, its data has been successfully used in a wide range of scientific applications such as weather forecasting, ionosphere and the Earth's gravity studies (Yue et al., 2010). The COSMIC/ FORMOSAT-3 Radio Occultation (RO) data is available to users from the COSMIC Data Analysis and Archive Centre (CDAAC) at the University Corporation for Atmospheric Research (UCAR) 
website http://cdaac-www.cosmic.ucar.edu/cdaac/products.html for authorised users. The RO processed data comes in three types, namely (1) COSMIC2013: consisting of reprocessed data using enhanced processing strategies resulting in higher RO counts, (2) COSMIC postprocessed data with a typical latency of six weeks and (3) COSMICRT containing real-time data with a latency of a few hours. These data sets are available in the netCDF-4 format.

The COSMIC2013 reprocessed data was considered in this study. Of the several versions of the available atmospheric profiles, the wetPrf product was used, which contains the profiles of temperature, water vapour pressure and refractivity at $0.1 \mathrm{~km}$ intervals up to an altitude of $40 \mathrm{~km}$. The data is not regularly gridded in latitude and longitude, but is rather limited to where the RO point occurred in relation to the COSMIC and GPS satellite line-of-sight. Once the water vapour pressure and temperature are interpolated at a given location and time, the ZWD may be calculated using Eq 15. One issue with the COSMIC RO data is that there is not enough spatial and temporal resolution to accurately interpolate the atmospheric variables at any given location and time, which makes the interpolation infeasible at some locations (Yue et al., 2010). Figure 1 shows the RO locations in the Australian region for one day of the COSMIC data on 8 December 2016, and Figure 2 shows the Pressure, water vapour pressure and temperature profiles for the 634 globally located RO points on the same day. As shown, only 39 RO points were observed in the Australian region during that day and there were less than ten points within the landmass. Thus this data could not be used in this study. However, this situation is likely to improve in the future as more COSMIC satellites are launched.

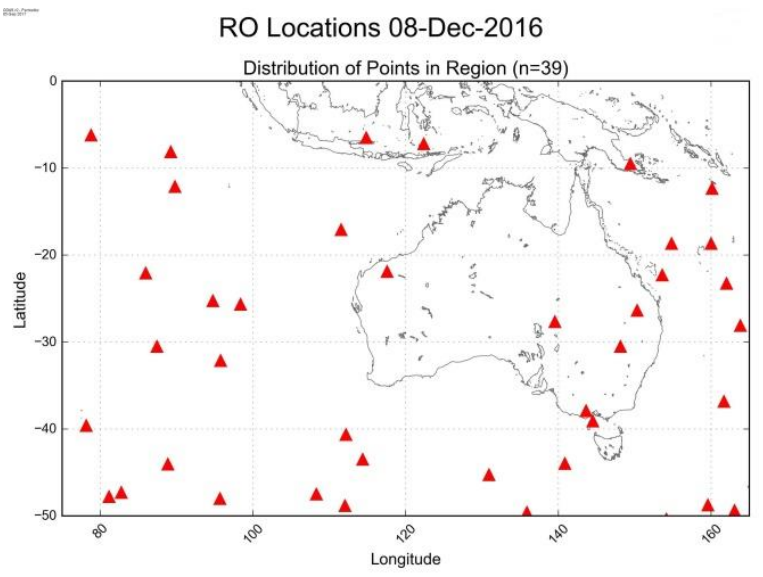

Figure 1: Radio Occultation locations for $39 \mathrm{RO}$ points in the Australian region from COSMIC data on 8 December 2016.
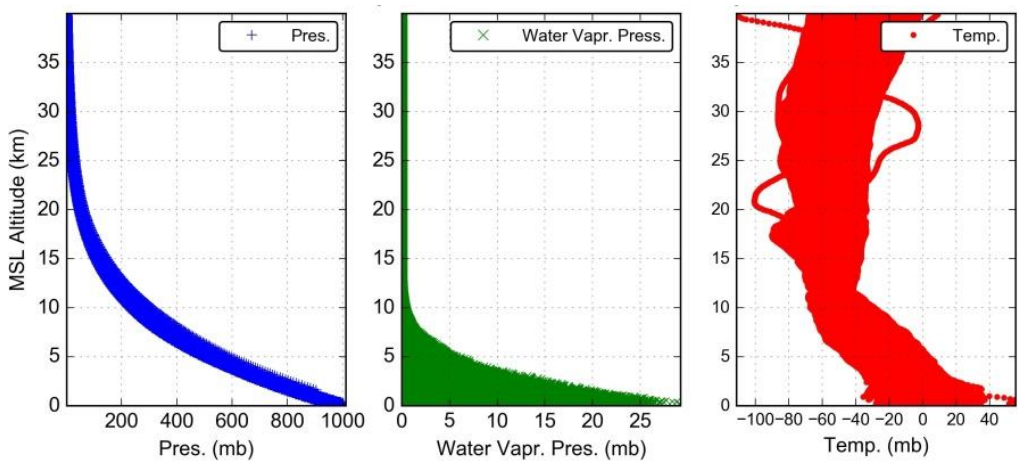

Figure 2: Pressure, water vapour pressure and temperature profiles for the 634 globally located RO data points from COSMIC data on 8 December 2016. 


\section{Analysis of ZTD models}

In this section we analyse the performance of each of the presented troposphere models by comparing the estimated ZTD from employing these models with the values obtained from the precise IGS ZTD product at selected stations in Australia. The stations analysed are distributed over the Australian continent and include Hobart (HOB2), Alice Springs (ALIC), Yarragadee (YAR2) and Townsville (TOW2).

\begin{tabular}{|l|l|l|l|l|l|}
\hline \multicolumn{1}{|c|}{ Site } & $\begin{array}{l}\text { Latitude } \\
\text { (degrees) }\end{array}$ & $\begin{array}{l}\text { Longitude } \\
\text { (degrees) }\end{array}$ & $\begin{array}{l}\text { Ellipsoidal } \\
\text { Height }(\mathrm{h})(\mathrm{m})\end{array}$ & $\begin{array}{l}\text { Orthometric } \\
\text { Height }(\mathrm{H})\end{array}$ & $\begin{array}{l}\text { Difference } \\
h-H(\mathrm{~m})\end{array}$ \\
\hline ALIC & S 23.670 & E 133.886 & 603.245 & 587.643 & 15.602 \\
\hline HOB2 & S 42.805 & E 147.439 & 41.044 & 44.756 & -3.712 \\
\hline TOW2 & S 19.269 & E 147.056 & 88.109 & 29.474 & 58.635 \\
\hline YAR2 & S 29.047 & E 115.347 & 241.289 & 266.528 & 25.239 \\
\hline
\end{tabular}

shows the ITRF2008 geodetic coordinates (latitude, longitude and ellipsoid height) for these stations, extracted from the Asia Pacific Reference Frame (APREF) solution produced by Geoscience Australia for GPS week 1877. The Orthometric heights are also given, which were obtained from the Australian national geodetic database (www.ga.gov.au/ngrs). Since these stations are IGS reference stations, they have precise ZTD estimates available as an IGS product. These were used as reference values for comparison with results from the tested models. The analysis pertains to the full year from 1 January to 31 December 2016. The GRIB2 data was only available for approximately seven months of this period, due to connection issues that result in data outages.

Figures 3-6 show the time series of the ZHD and ZWD values from the GPT2 and GPT2w empirical models, and the ECMWF and BoM NWM data at ALIC, HOB2, TOW2 and YAR2 respectively. As shown in the figures, the ZHD values from GPT2 and GPT2w have millimetre level agreement with each other at all four sites. However, the discrepancy between these and the ECMWF model was at the $0.02-0.04 \mathrm{~m}$ level at YAR2 and up to $0.10 \mathrm{~m}$ at TOW2. Note that the ECMWF ZHD values are based on ellipsoidal heights on a low resolution DEM. Thus this observed discrepancy may be attributed to the low resolution of DEM and the accuracy of geoid-ellipsoid undulation model at this location. The ZHD from BoM data is in agreement with the GPT2/ GPT2w models at the 0.01-0.02m level. The IGS ZWD in these figures is calculated by subtracting the ZHD determined from GPT $2 \mathrm{w}$ from the IGS ZTD. Overall, the mean and standard deviations (std) of the difference between the modelled ZWD and the IGS ZWD were mean $=0.031 \mathrm{~m}$, std $=0.065 \mathrm{~m}$, for BoM; mean=$0.061 \mathrm{~m}$, std $=0.076 \mathrm{~m}$ for ECMWF; mean $=-0.048 \mathrm{~m}$, std $=0.115 \mathrm{~m}$ for $\mathrm{GPT} 2$; mean $=-0.039 \mathrm{~m}$, $\mathrm{std}=0.105 \mathrm{~m}$ for GPT $2 \mathrm{w}$. Thus, the BoM derived ZWD was the most accurate and precise at these four tested sites.

Table 1: ITRF08 Geographical coordinates of the test points from APREF solution for week 1877 and Orthometric height from the Australian national geodetic database.

\begin{tabular}{|l|l|l|l|l|l|}
\hline Site & $\begin{array}{l}\text { Latitude } \\
(\text { degrees })\end{array}$ & $\begin{array}{l}\text { Longitude } \\
\text { (degrees) }\end{array}$ & $\begin{array}{l}\text { Ellipsoidal } \\
\text { Height }(\mathrm{h})(\mathrm{m})\end{array}$ & $\begin{array}{l}\text { Orthometric } \\
\text { Height }(\mathrm{H})\end{array}$ & $\begin{array}{l}\text { Difference } \\
h-H(\mathrm{~m})\end{array}$ \\
\hline ALIC & S 23.670 & E 133.886 & 603.245 & 587.643 & 15.602 \\
\hline HOB2 & S 42.805 & E 147.439 & 41.044 & 44.756 & -3.712 \\
\hline TOW2 & S 19.269 & E 147.056 & 88.109 & 29.474 & 58.635 \\
\hline YAR2 & S 29.047 & E 115.347 & 241.289 & 266.528 & 25.239 \\
\hline
\end{tabular}



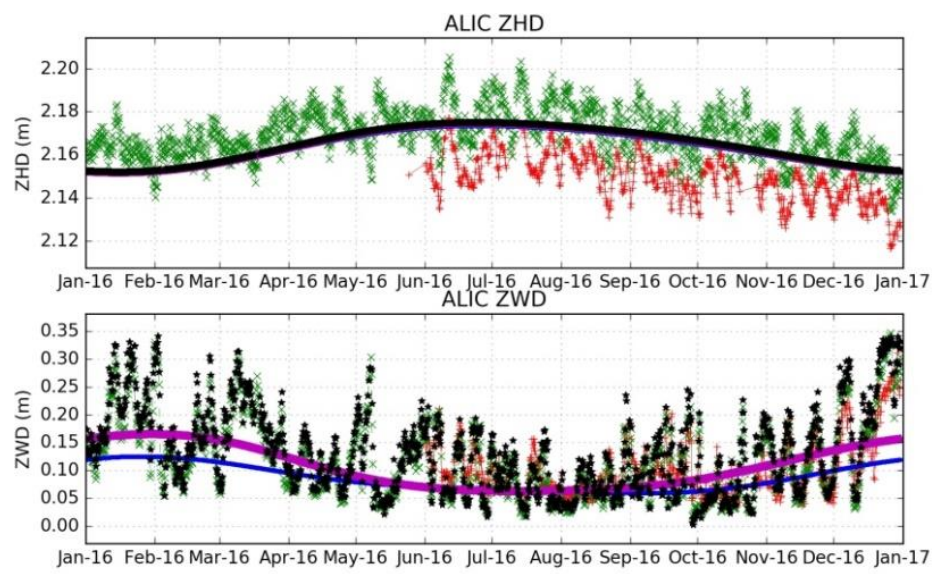

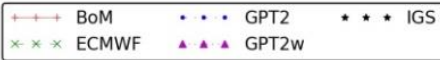

Figure 3: Time series of the ZHD and ZWD from the GPT2 and GPT2w empirical models, and ECMWF and BoM numerical weather model data for one year at ALIC site.
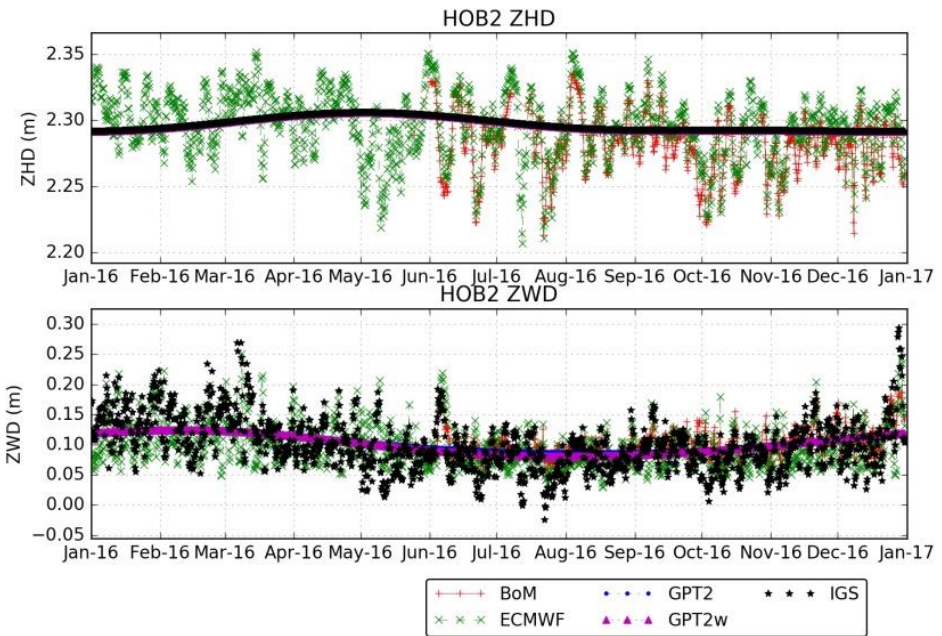

Figure 4: Time series of the ZHD and ZWD from the GPT2 and GPT2w empirical models, and ECMWF and BoM numerical weather model data for one year at HOB2 site.

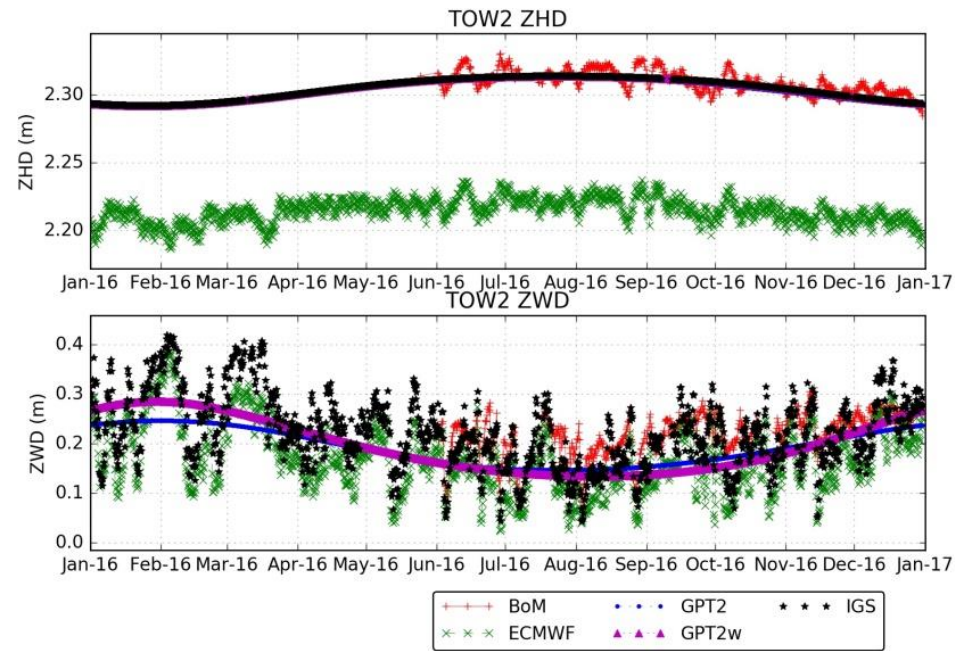

Figure 5: Time series of the ZHD and ZWD from the GPT2 and GPT2w empirical models, and ECMWF and BoM numerical weather model for one year data at TOW2 site. 


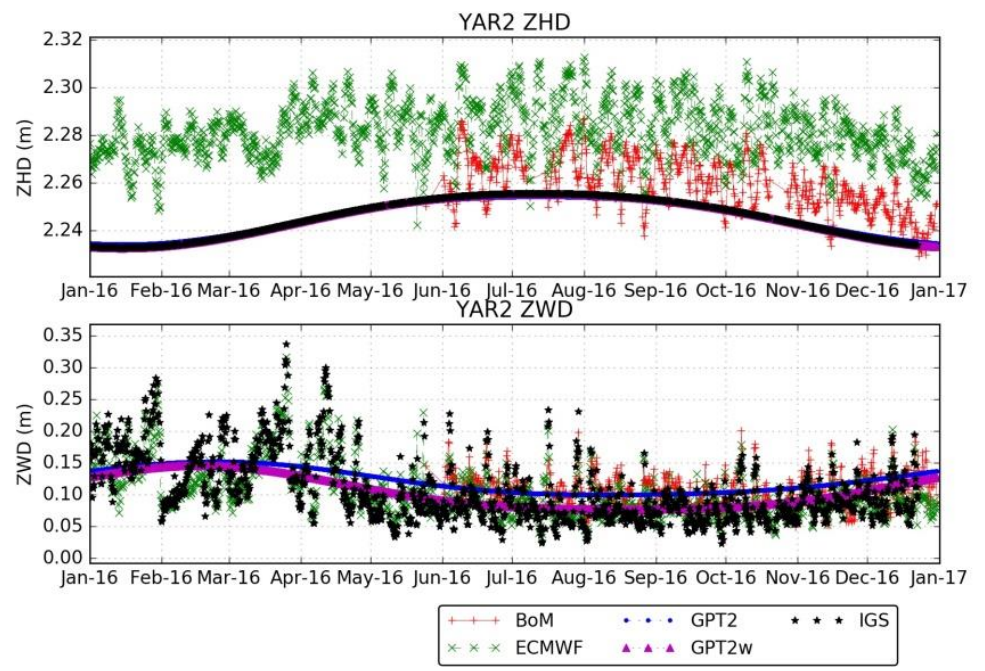

Figure 6: Time series of the ZHD and ZWD from the GPT2 and GPT2w empirical models, and ECMWF and BoM numerical weather model data for one year at YAR2 site.

From Figures 3-6, it is apparent that there are seasonal patterns for the troposphere accuracy for the different models at the four selected sites. We extracted monthly mean relative humidity and rainfall data from the BoM website (http://www.bom.gov.au/climate/data/) to gain more insight into these patterns. The data was extracted from weather stations located at local airports close to the GNSS stations, where Miorawa Airport was the closest to YAR2, Alice Springs Airport was the closest to ALIC, Townsville Aero was closest to TOW2 and Hobart Airport was closest to HOB2. As shown in Figure 7, the rainfall and relative humidity profiles differ considerably at these four sites because of their geographic locations and unique weather patterns. It is known from a previous study by Zhou et al. (2017) that the accuracy of NWM decreases in some areas due complex weather changes.

For TOW2, the offset in ZTD determined from BoM and IGS is more visible in the ZWD component. The ZWD at this site is comparatively noisier with a range of $0.4 \mathrm{~m}$, which indicates greater variability in the atmospheric moisture profiles. This may be because TOW2 is in a tropical zone close to the coast, where there is increased relative humidity throughout the year, as shown in Figure 7. At ALIC, the ZWD from BoM NWM is in good agreement with the IGS ZWD, but the overall standard deviation for ZTD is relatively higher at $0.043 \mathrm{~m}$. The ZWD profile at ALIC shows more variation during the Northern Territory wet season, which spans from November until April, and is characterised by increased rain and storms. The impact of the wet season during this period is visible in Figure 3. Despite the higher rain during this period, the relative humidity is low due to the increased temperatures in the warmer summer months. At HOB2, Figure 4 shows close agreement between the BoM NWM and IGS in the ZHD as well as ZWD components. This site has comparatively lesser variation in the ZWD profile, which may be due to the comparatively lesser variation in rainfall and relative humidity throughout the year. The YAR2 site also has lesser variation in the ZWD for most part of the year, except for Mar to May as shown in Figure 7. This site has higher rainfall from May to September, which correlates with the increased relative humidity. The increased ZWD variability may be due to the complex change from dry to wet season between Mar to May. 


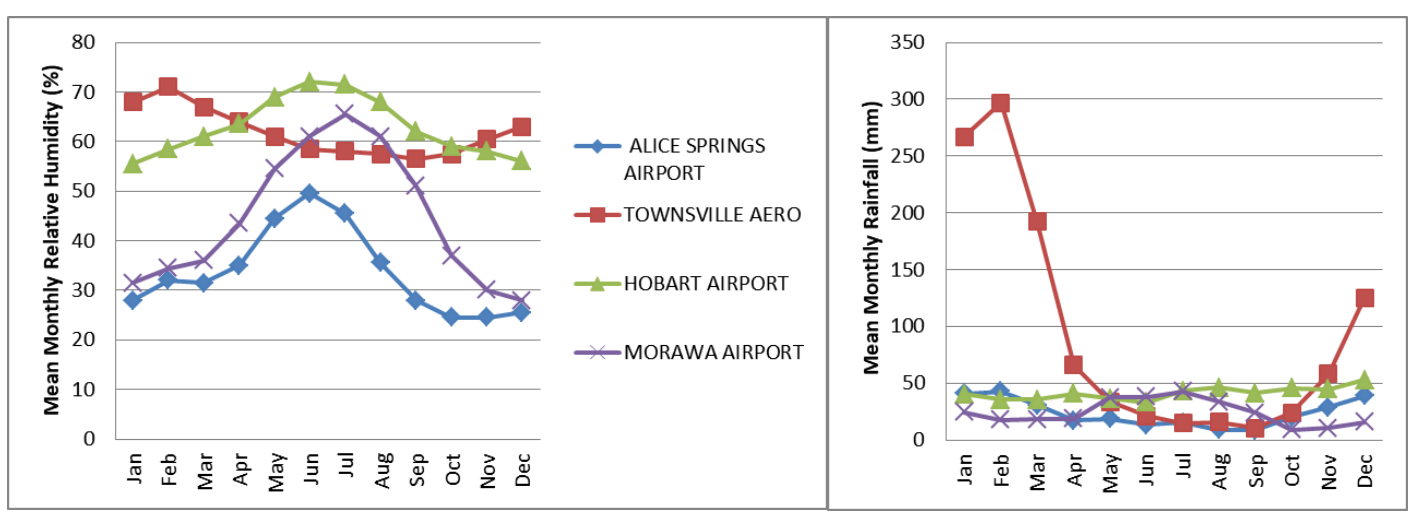

Figure 7: Mean monthly relative humidity (left) and rainfall (right) data at the four selected sites, extracted from the BoM website (http://www.bom.gov.au/climate/data/).

The ZTD from these models were compared to the IGS ZTD product available for these stations. Figures 8-11 show histograms of the difference between the ZTD obtained from IGS and those calculated as the sum of ZHD and ZWD from the GPT2 and GPT2w empirical models, and ECMWF and BoM NWM data. As shown, the agreement of ZTD between IGS and NWMs is better than the empirical models and $95 \%$ of the differences are within the range $\pm 0.2 \mathrm{~m}$, with the majority within $\pm 0.1 \mathrm{~m}$. The mean and standard deviations (std) of these differences are also summarised in Table 2 for the four sites. As shown, the precisions of the ZTD from NWM datasets, represented by the standard deviations, are consistently better than the GPT2 and GPT2w empirical models at the four sites. The GPT2w model gave more accurate ZTD values compared to GPT2, with a slight improvement in precision at the $\mathrm{mm}$ level. The ZTD from ECMWF model gave precise results at ALIC (mean $=0.007 \mathrm{~m}$, $\mathrm{std}=0.018 \mathrm{~m}$ ) and HOB2 (mean $=0.006 \mathrm{~m}$, std $=0.026 \mathrm{~m}$ ), both of which have low discrepancy between ellipsoid and orthometric height. However, results were poor at TOW2 and YAR2 due to the low resolution of DEM used in the ECMWF model, as discussed earlier. The ZTD from BoM data gave consistent results at all four sites with mean errors between $-0.034 \mathrm{~m}$ and $0.029 \mathrm{~m}$ and standard deviations better than $0.045 \mathrm{~m}$. Overall, use of BoM NWM data gave more precise and accurate ZTD values than any other of the tested models. The next section analyses the PPP performance when constraining the ZTD with the BoM NWM, the proven best model.

Table 2: Mean and standard deviation (std) of the difference between the IGS ZTD and modelled ZTDs from GPT2, GPT2w, ECMWF and BoM.

\begin{tabular}{|c|c|c|c|c|c|c|c|c|}
\hline \multirow[t]{2}{*}{ Site } & \multicolumn{2}{|c|}{$\begin{array}{l}Z T D_{I G S} \\
-Z T D_{G P T 2}\end{array}$} & \multicolumn{2}{|c|}{$\begin{array}{l}Z T D_{I G S} \\
-Z T D_{G P T 2 w}\end{array}$} & \multicolumn{2}{|c|}{$\begin{array}{l}Z T D_{I G S} \\
-Z T D_{E C M W F}\end{array}$} & \multicolumn{2}{|c|}{$Z T D_{I G S}-Z T D_{\text {Bom }}$} \\
\hline & $\operatorname{Mean}(\mathrm{m})$ & $\begin{array}{l}\text { Std. } \\
\text { (m) }\end{array}$ & $\operatorname{Mean}(\mathrm{m})$ & $\begin{array}{l}\text { Std. } \\
\text { (m) }\end{array}$ & $\operatorname{Mean}(\mathrm{m})$ & $\begin{array}{l}\text { Std. } \\
\text { (m) }\end{array}$ & $\operatorname{Mean}(\mathrm{m})$ & $\begin{array}{l}\text { Std. } \\
\text { (m) }\end{array}$ \\
\hline ALIC & 0.048 & 0.064 & 0.025 & 0.062 & 0.007 & 0.018 & 0.029 & 0.043 \\
\hline HOB2 & -0.002 & 0.039 & 0.000 & 0.038 & 0.006 & 0.026 & 0.001 & 0.023 \\
\hline TOW2 & 0.030 & 0.061 & 0.023 & 0.062 & 0.145 & 0.029 & -0.026 & 0.043 \\
\hline YAR2 & -0.014 & 0.043 & 0.004 & 0.042 & -0.035 & 0.027 & -0.034 & 0.028 \\
\hline
\end{tabular}



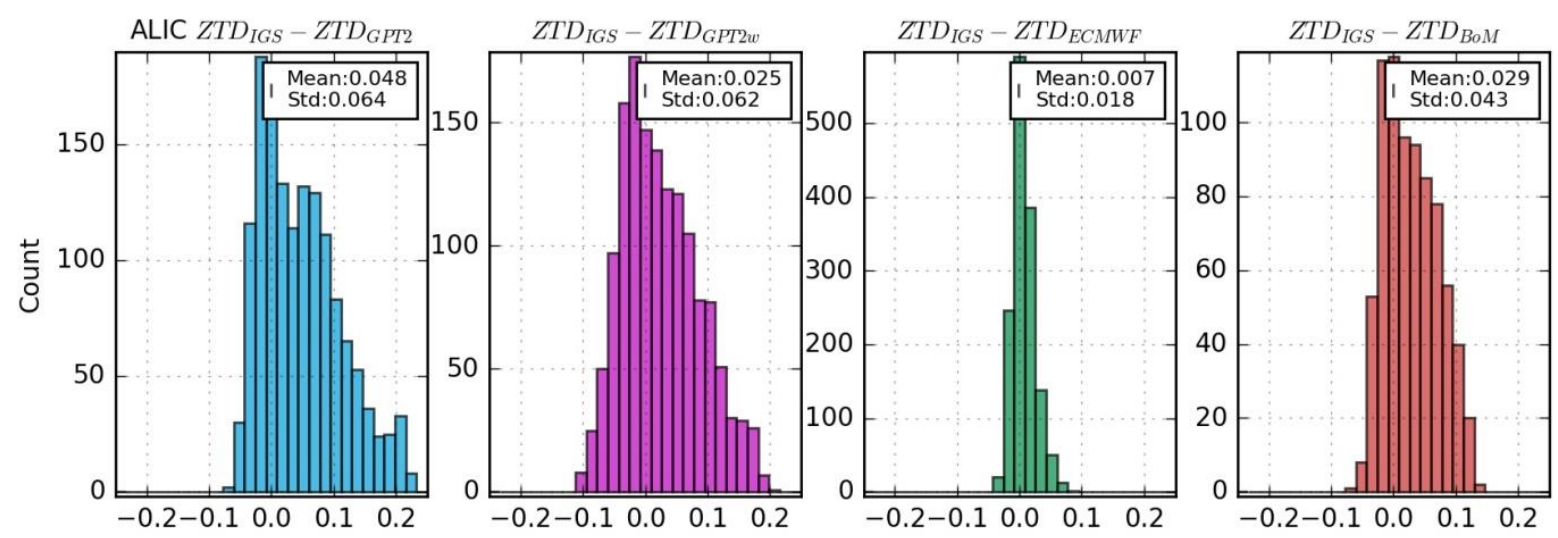

Figure 8: Histograms of the difference between IGS ZTD and model ZTDs from GPT2, GPT2w, ECMWF and BoM, from left to right, at station ALIC.
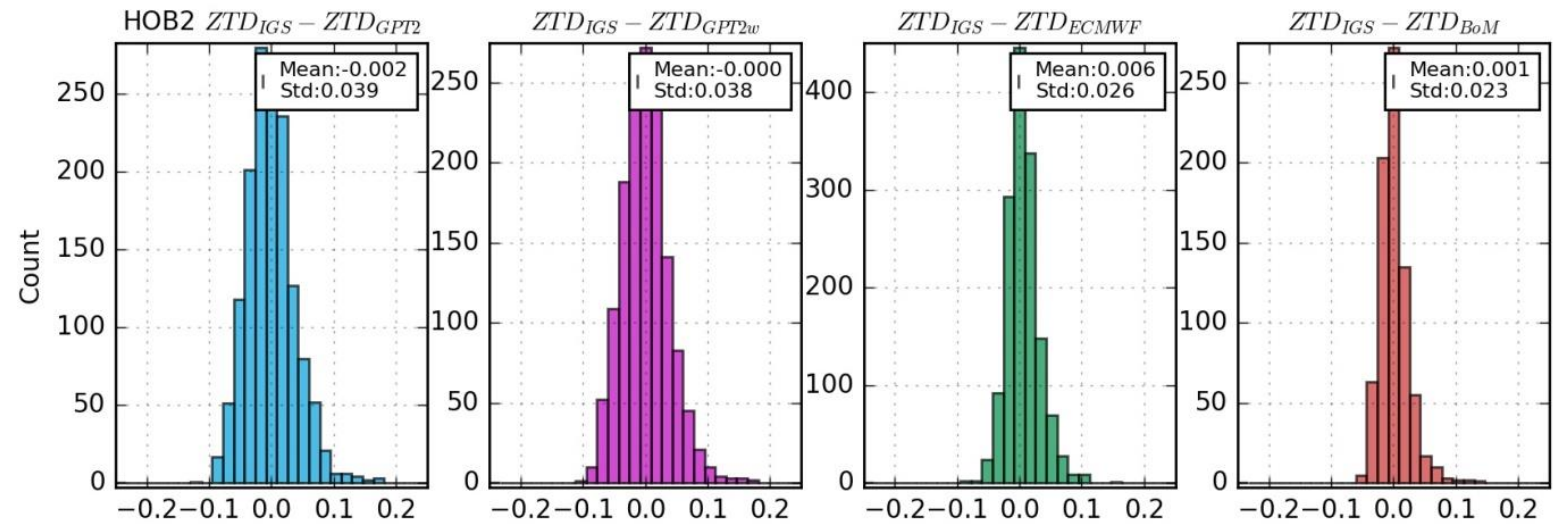

Figure 9: Histograms of the difference between IGS ZTD and model ZTDs from GPT2, GPT2w, ECMWF and BoM, from left to right, at station HOB2.

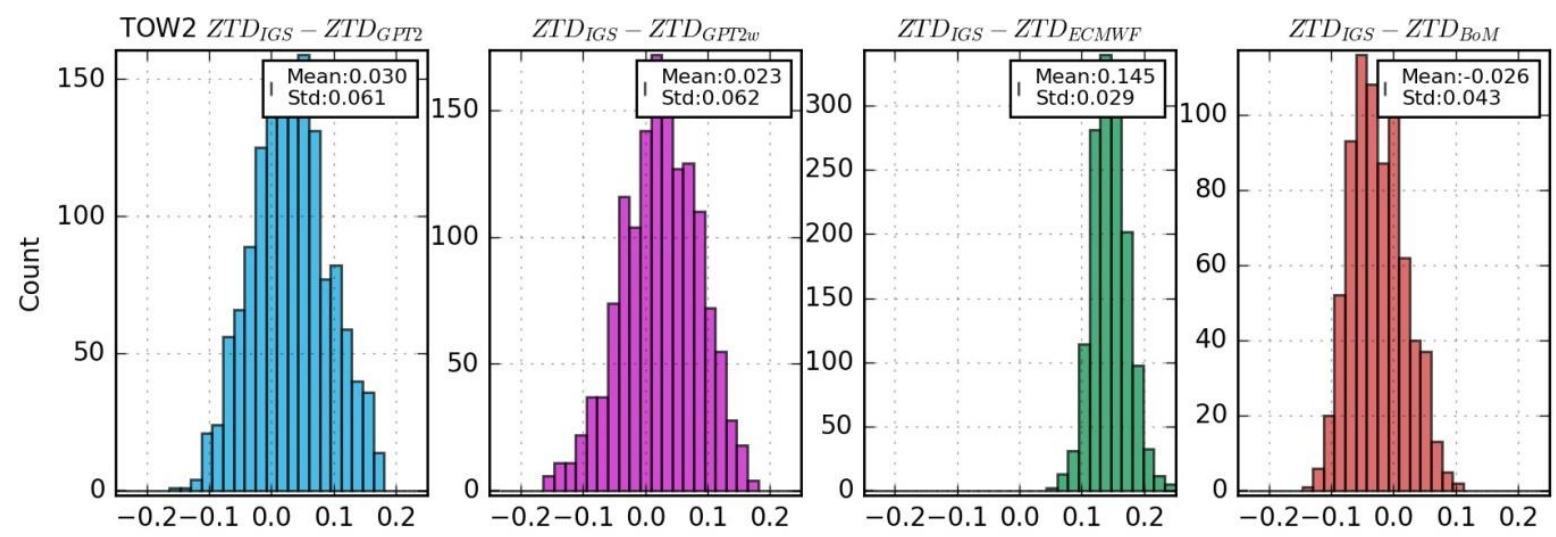

Figure 10: Histograms of the difference between IGS ZTD and model ZTDs from GPT2, GPT2w, ECMWF and BoM, from left to right, at station TOW2. 


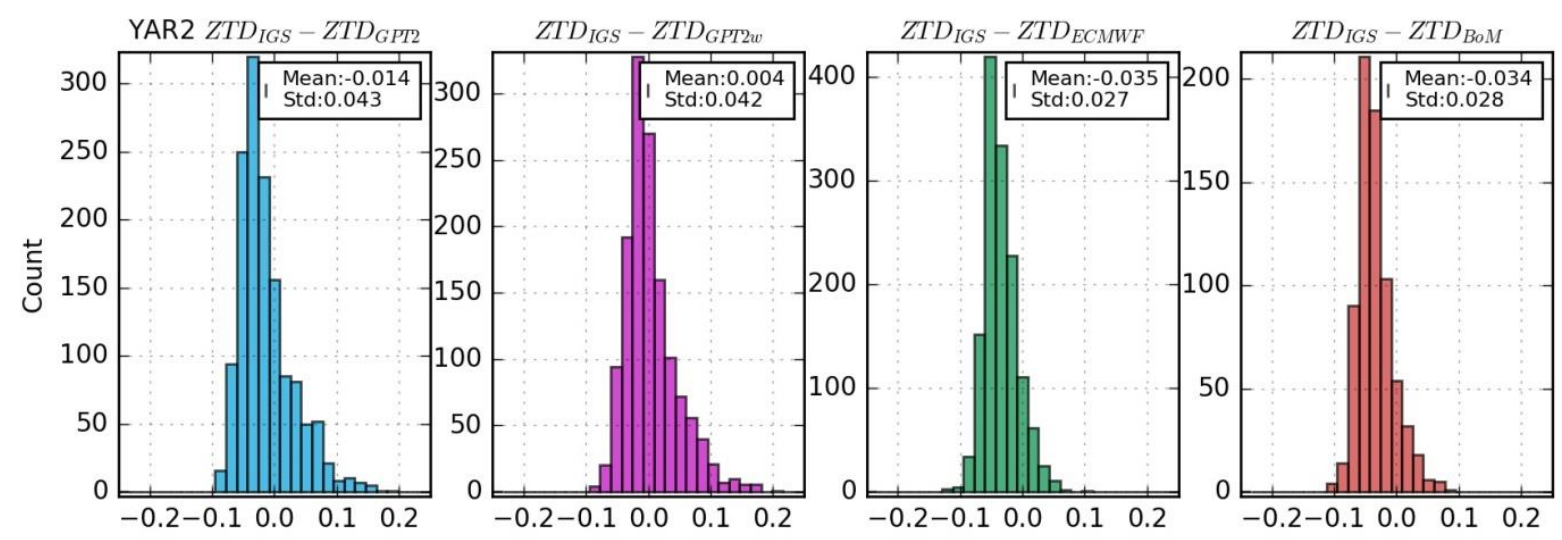

Figure 11: Histograms of the difference between IGS ZTD and model ZTDs from GPT2, GPT2w, ECMWF and BoM, from left to right, at station YAR2.

\section{PPP Performance Analysis with the BoM NWM Tropospheric Model}

This section analyses the performance of PPP in terms of the convergence time taken to achieve sub-decimetre positioning errors, and the accuracy after convergence is achieved. The PPP model with and without the ZTD aiding was implemented using Kalman filter; i.e. processing the data by constraining the ZTD from BoM NWM model and the stds given in the last column of Table 2, and next processing the same data in the conventional method by estimating ZTD as one of the parameters. In both cases, a satellite elevation cut-off angle of $10^{0}$ was used. The triple frequency low noise and ionosphere free linear combinations for carrier phase and code measurements were used when constraining the ZTD using the BoM NWM, and in the conventional case of estimating it as a parameter. In the conventional method, the ZHD was modelled with Eq. 14 with the Neill's hydrostatic mapping function (Neil, 1996), whereas the ZWD was determined as an unknown parameter.

\subsection{PPP Results}

Results are compared in terms of solution convergence time taken to achieve subdecimetre accuracy in the horizontal dimension (2D), including North (N) and East (E) position components, as well as the vertical dimension. The $2 \mathrm{D}$ convergence time is defined as the time when horizontal positional accuracy of $0.10 \mathrm{~m}$ is reached and maintained thereafter, indicating stability of the float ambiguity solution. Likewise, the N, E and vertical convergence time defines when sub-decimetre accuracy is achieved in N, E and vertical components, respectively. The accuracy is defined in terms of the root mean squared error (RMSE) of the estimated positions after convergence is achieved with respect to the known station coordinates obtained from the APREF solution. The results from constraining the troposphere with the BoM NWM is compared to the case where the troposphere is estimated as an unknown parameter. Appropriate weighting was applied to the BoM NWM derived ZTD values, based on the analysis in the previous section. In addition, we applied a constraint based on the real accuracy of the ZTD determined from the long term analysis. This constrained PPP model accounts for the imperfections in the ZTD derived from the BoM NWM model, mainly due to limitations in accurately modelling complex weather changes. The study was conducted with simulated multi-constellation triple frequency GNSS data with 32 GPS, 17 Galileo and 14 Beidou satellites at the sites ALIC, HOB2, TOW2 and YAR2, with $30 \mathrm{sec}$ epoch interval and 5 day's of data from 3-7 June 2016. 
For demonstration, the proposed model was firstly assessed for HOB2 assuming a totally known troposphere delay (i.e., troposphere with zero error). Although this is not feasible in practice, it demonstrates the ultimate benefits of modelling out the troposphere if it is accurately known. Estimating the troposphere as an unknown parameter in the PPP model resulted in a convergence time of 6.0 minutes to reach a $2 \mathrm{D}$ accuracy of $0.10 \mathrm{~m}$, and a convergence time of 12.5 minutes to reach a $2 \mathrm{D}$ accuracy of $0.05 \mathrm{~m}$. When the troposphere is exactly known from the IGS ZTD model, the convergence time to reach $2 \mathrm{D}$ accuracy of $0.10 \mathrm{~m}$ was $5.5 \mathrm{~min}$, and a $2 \mathrm{D}$ accuracy of $0.05 \mathrm{~m}$ was reached after 11.5 minutes. A satellite elevation cut-off angle of 10 degrees was used in both cases. Therefore, modest improvements in convergence time of 0.5 and 1 minute was achieved to reach $0.1 \mathrm{~m}$ and $0.05 \mathrm{~m}$ accuracy, respectively. These convergence times may appear over optimistic, noting that simulated data was used, which did not include multipath. Moreover, the enhanced triple frequency model was implemented, which has significantly better performance than the traditional dual-frequency model (Deo and El-Mowafy, 2016).

For the case of using the BoM NWM to constrain the ZTD, Table 3 shows the convergence time required to achieve $0.1 \mathrm{~m}$ and $0.05 \mathrm{~m}$ accuracy in $2 \mathrm{D}, \mathrm{N}, \mathrm{E}$ and vertical components compared with the case of estimating the troposphere as a parameter. As the table shows, the results practically did not change. There was however a slight improvement by 0.5 minutes in the BoM constrained model to reach $0.1 \mathrm{~m}$ vertical accuracy at HOB2 and at TOW2 to reach $0.05 \mathrm{~m}$ accuracy. In terms of the accuracy achieved after convergence, Table 4 compares the RMSE in the 2D, N, E and vertical components after convergence of the PPP solutions to reach $0.1 \mathrm{~m}$ and $0.05 \mathrm{~m}$ at the four sites. As the table shows, there are slight improvements found at the millimetre level at ALIC, HOB2 and YAR2, the results are unchanged at TOW2.

Table 3: Convergence time taken to reach accuracy of $0.1 \mathrm{~m}$ and $0.05 \mathrm{~m}(2 \mathrm{D}$, North, East and Vertical) for the PPP model with troposphere estimation, and when using BoM NWM constrained troposphere.

\begin{tabular}{|c|c|c|c|c|c|c|c|c|c|c|}
\hline \multirow[t]{2}{*}{ Site } & \multirow[t]{2}{*}{ Troposphere Model } & \multirow{2}{*}{$\begin{array}{l}\text { Average } \\
\text { number of } \\
\text { satellites }\end{array}$} & \multicolumn{4}{|c|}{$\begin{array}{l}\text { Convergence time to reach } \\
0.1 \mathrm{~m}(\min )\end{array}$} & \multicolumn{4}{|c|}{$\begin{array}{l}\text { Convergence time to reach } \\
0.05 \mathrm{~m} \text { accuracy }(\mathrm{min})\end{array}$} \\
\hline & & & $2 \mathrm{D}$ & $\mathrm{N}$ & $\mathrm{E}$ & Vert. & $2 \mathrm{D}$ & $\mathrm{N}$ & $\mathrm{E}$ & Vert. \\
\hline \multirow[t]{2}{*}{$\overline{\text { ALIC }}$} & ZTD Estimated & 20 & 6.5 & 4.0 & 4.0 & 15.5 & 22.0 & 7.5 & 12.0 & 32.0 \\
\hline & BoM Constrained & 20 & 6.5 & 4.0 & 4.0 & 15.5 & 22.0 & 7.5 & 12.0 & 32.0 \\
\hline \multirow[t]{2}{*}{ HOB2 } & ZTD Estimated & 18 & 6.5 & 3.5 & 4.0 & 12.5 & 20.0 & 8.0 & 11.5 & 24.0 \\
\hline & BoM Constrained & 18 & 6.5 & 3.5 & 4.0 & 12.0 & 20.0 & 8.0 & 11.5 & 24.0 \\
\hline \multirow[t]{2}{*}{ TOW2 } & ZTD Estimated & 20 & 7.0 & 3.0 & 5.0 & 13.5 & 21.5 & 6.5 & 15.0 & 28.0 \\
\hline & BoM Constrained & 20 & 7.0 & 3.0 & 5.0 & 13.5 & 21.5 & 6.5 & 15.0 & 27.5 \\
\hline \multirow[t]{2}{*}{ YAR2 } & ZTD Estimated & 21 & 7.0 & 4.0 & 4.0 & 13.5 & 16.5 & 8.5 & 11.0 & 26.5 \\
\hline & BoM Constrained & 21 & 7.0 & 4.0 & 4.0 & 13.5 & 16.5 & 8.5 & 11.0 & 26.5 \\
\hline
\end{tabular}

Table 4: RMSE after convergence to $0.1 \mathrm{~m}$ and $0.05 \mathrm{~m}$ accuracy (2D and Vertical) for the PPP model with troposphere estimation \& when using BoM NWM constrained troposphere.

\begin{tabular}{|c|c|c|c|c|c|c|c|c|c|}
\hline \multirow[t]{2}{*}{ Site } & \multirow[t]{2}{*}{ Troposphere Model } & \multicolumn{4}{|c|}{$\begin{array}{l}\text { Mean RMSE } \\
\text { convergence (m) }\end{array}$} & \multicolumn{4}{|c|}{$\begin{array}{lrll}\begin{array}{l}\text { Mean } \\
\text { convergence }(\mathrm{m})\end{array} & \text { after } & 0.05 \mathrm{~m} \\
\end{array}$} \\
\hline & & $2 \mathrm{D}$ & $\mathrm{N}$ & $\mathrm{E}$ & Vert. & $2 \mathrm{D}$ & $\mathrm{N}$ & $\mathrm{E}$ & Vert. \\
\hline \multirow[t]{2}{*}{ ALIC } & ZTD Estimated & 0.045 & 0.024 & 0.039 & 0.047 & 0.037 & 0.021 & 0.033 & 0.034 \\
\hline & BoM Constrained & 0.045 & 0.023 & 0.038 & 0.046 & 0.037 & 0.020 & 0.033 & 0.034 \\
\hline \multirow[t]{2}{*}{ HOB2 } & ZTD Estimated & 0.045 & 0.025 & 0.036 & 0.043 & 0.038 & 0.021 & 0.032 & 0.035 \\
\hline & BoM Constrained & 0.045 & 0.024 & 0.036 & 0.042 & 0.037 & 0.020 & 0.032 & 0.034 \\
\hline \multirow[t]{2}{*}{ TOW2 } & ZTD Estimated & 0.043 & 0.021 & 0.038 & 0.043 & 0.034 & 0.018 & 0.031 & 0.031 \\
\hline & BoM Constrained & 0.043 & 0.021 & 0.038 & 0.043 & 0.034 & 0.018 & 0.031 & 0.031 \\
\hline \multirow[t]{2}{*}{ YAR2 } & ZTD Estimated & 0.040 & 0.024 & 0.032 & 0.044 & 0.034 & 0.021 & 0.027 & 0.034 \\
\hline & BoM Constrained & 0.040 & 0.024 & 0.032 & 0.044 & 0.034 & 0.020 & 0.027 & 0.034 \\
\hline
\end{tabular}



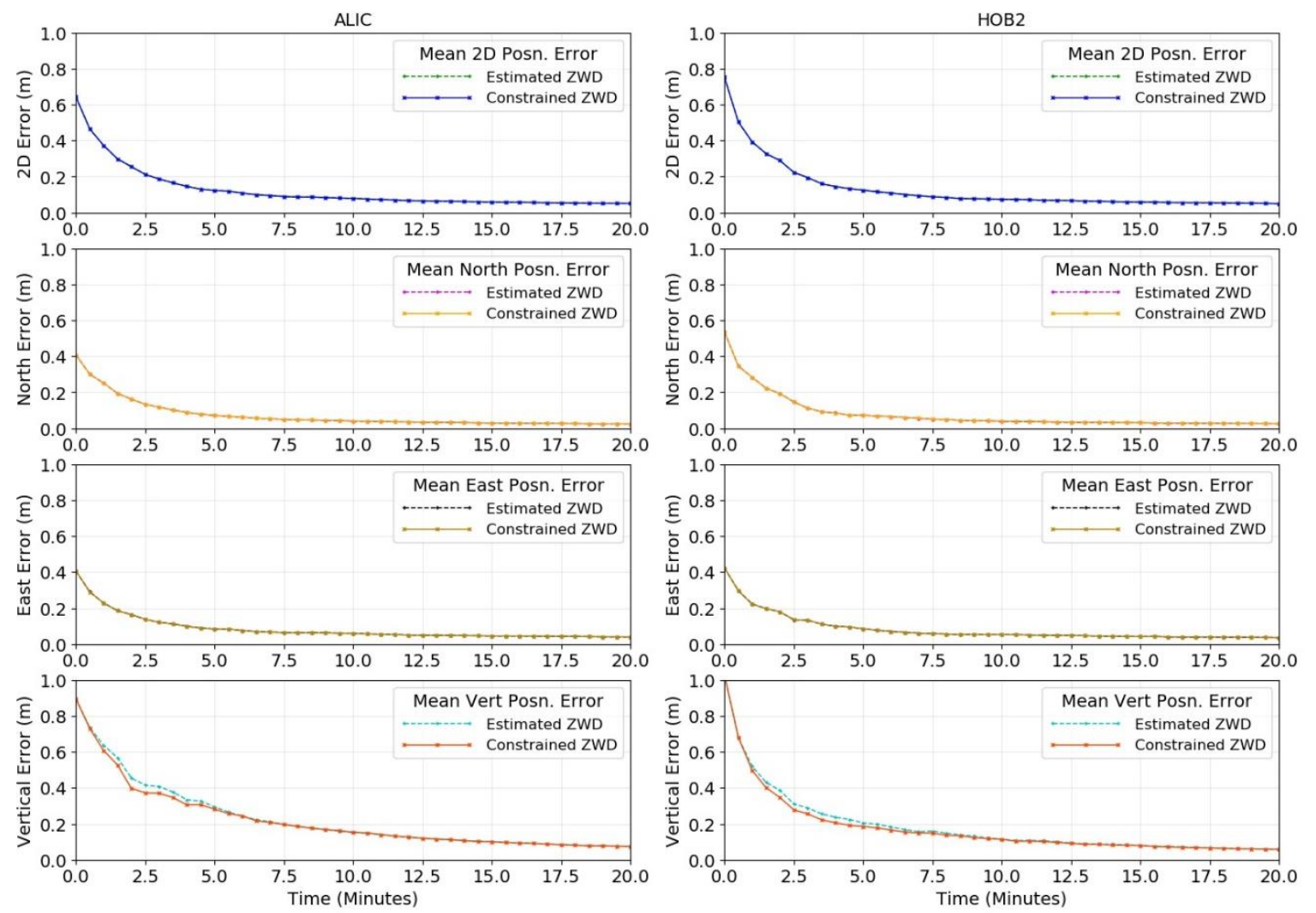

Figure 12: Comparison of PPP positioning errors in 2D and absolute values in North, East and Vertical components for the triple frequency PPP model when estimating the troposphere as a parameter and constraining the troposphere using BoM GRIB2 data at ALIC (left) and HOB2 (right).

The mean positioning errors of the hourly PPP solutions for the five days were computed after convergence periods of 2, 3, 5, 10 and 20 minutes after the PPP initialisation times. This was done for the 2D, N, E and vertical components at the four sites. Results are given in Table 5. One of the key findings from this table is that the accuracy of the BoM constrained troposphere model achieved faster convergence in the vertical component for the first few minutes of convergence, compared to the PPP model which estimated the troposphere as a parameter. The BoM constrained troposphere model PPP had better vertical accuracy than the former model by $0.036-0.058 \mathrm{~m}$ after 2 minutes, $0.023-0.038 \mathrm{~m}$ after 3 minutes and 0.013 $0.020 \mathrm{~m}$ after 5 minutes of PPP initialisation. After 6-7 minutes of convergence, both models performed at similar level of accuracy at all the four sites. 

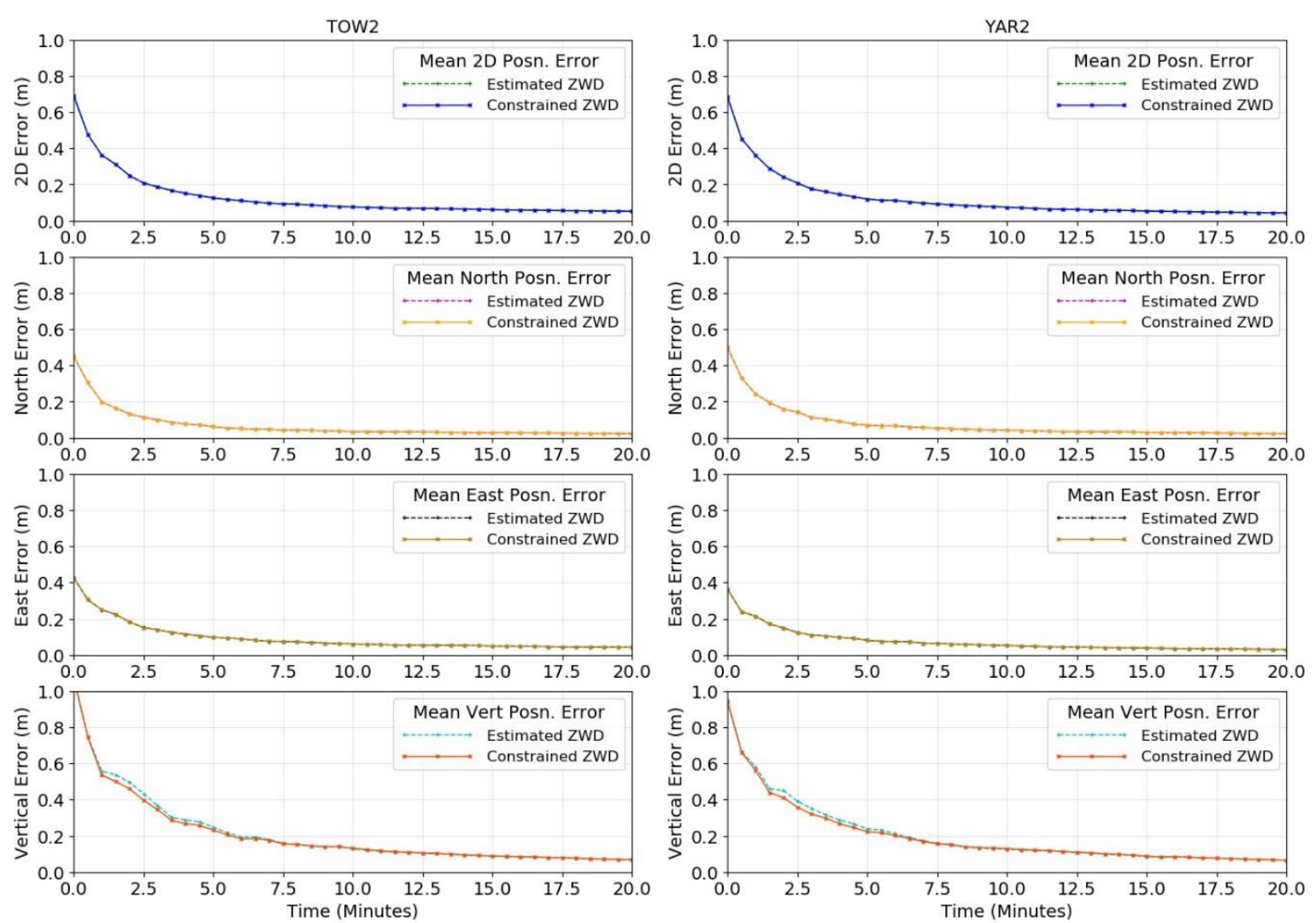

Figure 13: Comparison of PPP positioning errors in 2D and absolute values in North, East and Vertical components for the triple frequency PPP model when estimating the troposphere as a parameter and constraining the troposphere using BoM GRIB2 data at TOW2 (left) and YAR2 (right).

Table 5: Mean positioning errors in 2D, North, East and Vertical components after PPP initialisation times of 2, 3, 5, 10 and 20 minutes for the PPP model with tropospheric estimation and the PPP model with BoM NWM constrained troposphere.

\begin{tabular}{|c|c|c|c|c|c|c|c|c|c|c|c|}
\hline \multirow{2}{*}{\multicolumn{2}{|c|}{$\begin{array}{l}\text { Troposphere Model } \\
\text { Time since PPP } \\
\text { initialisation }\end{array}$}} & \multicolumn{5}{|c|}{ Estimated parameter } & \multicolumn{5}{|c|}{ BoM Constrained (diff) } \\
\hline & & $2 \mathrm{~min}$ & $3 \mathrm{~min}$ & $5 \mathrm{~min}$ & $10 \mathrm{~min}$ & $20 \mathrm{~min}$ & $2 \mathrm{~min}$ & $3 \min$ & $5 \mathrm{~min}$ & $10 \mathrm{~min}$ & $20 \mathrm{~min}$ \\
\hline \multirow{4}{*}{$\begin{array}{l}\text { HOB2 } \\
\text { Mean } \\
\text { RMSE } \\
(\mathrm{m})\end{array}$} & $2 \mathrm{D}$ & 0.289 & 0.194 & 0.124 & 0.073 & 0.049 & $\begin{array}{l}0.289 \\
(0.000)\end{array}$ & $\begin{array}{l}0.192 \\
(-0.002)\end{array}$ & $\begin{array}{l}0.124 \\
(0.000)\end{array}$ & $\begin{array}{l}0.074 \\
(+0.001)\end{array}$ & $\begin{array}{l}0.049 \\
(0.000)\end{array}$ \\
\hline & $\mathrm{N}$ & 0.193 & 0.112 & 0.073 & 0.038 & 0.025 & $\begin{array}{l}0.195 \\
(+0.002)\end{array}$ & $\begin{array}{l}0.112 \\
(0.000)\end{array}$ & $\begin{array}{l}0.072 \\
(-0.001)\end{array}$ & $\begin{array}{l}0.040 \\
(+0.002)\end{array}$ & $\begin{array}{l}0.026 \\
(+0.001)\end{array}$ \\
\hline & $\mathrm{E}$ & 0.179 & 0.133 & 0.085 & 0.052 & 0.035 & $\begin{array}{l}0.179 \\
(0.000)\end{array}$ & $\begin{array}{l}0.133 \\
(0.000)\end{array}$ & $\begin{array}{l}0.085 \\
(0.000)\end{array}$ & $\begin{array}{l}0.052 \\
(0.000)\end{array}$ & $\begin{array}{l}0.036 \\
(+0.001)\end{array}$ \\
\hline & Vert. & 0.386 & 0.289 & 0.205 & 0.115 & 0.059 & $\begin{array}{l}0.346 \\
(-0.040)\end{array}$ & $\begin{array}{l}0.255 \\
(-0.034)\end{array}$ & $\begin{array}{l}0.185 \\
(-0.020)\end{array}$ & $\begin{array}{l}0.114 \\
(-0.001)\end{array}$ & $\begin{array}{l}0.058 \\
(-0.001)\end{array}$ \\
\hline \multirow{4}{*}{$\begin{array}{l}\text { YAR2 } \\
\text { Mean } \\
\text { RMSE } \\
(\mathrm{m})\end{array}$} & $2 \mathrm{D}$ & 0.241 & 0.175 & 0.119 & 0.073 & 0.043 & $\begin{array}{l}0.241 \\
(0.000)\end{array}$ & $\begin{array}{l}0.176 \\
(+0.001)\end{array}$ & $\begin{array}{l}0.119 \\
(0.000)\end{array}$ & $\begin{array}{l}0.074 \\
(+0.001)\end{array}$ & $\begin{array}{l}0.043 \\
(0.000) \\
\end{array}$ \\
\hline & $\mathrm{N}$ & 0.158 & 0.113 & 0.069 & 0.042 & 0.024 & $\begin{array}{l}0.158 \\
(0.000) \\
\end{array}$ & $\begin{array}{l}0.114 \\
(+0.001)\end{array}$ & $\begin{array}{l}0.070 \\
(+0.001)\end{array}$ & $\begin{array}{l}0.042 \\
(0.000) \\
\end{array}$ & $\begin{array}{l}0.024 \\
(0.000)\end{array}$ \\
\hline & $\mathrm{E}$ & 0.149 & 0.110 & 0.081 & 0.051 & 0.030 & $\begin{array}{l}0.149 \\
(0.000) \\
\end{array}$ & $\begin{array}{l}0.110 \\
(0.000) \\
\end{array}$ & $\begin{array}{l}0.081 \\
(0.000) \\
\end{array}$ & $\begin{array}{l}0.052 \\
(+0.001) \\
\end{array}$ & $\begin{array}{l}0.030 \\
(0.000) \\
\end{array}$ \\
\hline & Vert. & 0.450 & 0.352 & 0.239 & 0.126 & 0.065 & $\begin{array}{l}0.411 \\
(-0.039) \\
\end{array}$ & $\begin{array}{l}0.320 \\
(-0.032) \\
\end{array}$ & $\begin{array}{l}0.223 \\
(-0.016)\end{array}$ & $\begin{array}{l}0.130 \\
(+0.004) \\
\end{array}$ & $\begin{array}{l}0.064 \\
(-0.001) \\
\end{array}$ \\
\hline \multirow{4}{*}{$\begin{array}{l}\text { ALIC } \\
\text { Mean } \\
\text { RMSE } \\
(\mathrm{m})\end{array}$} & $2 \mathrm{D}$ & 0.255 & 0.187 & 0.123 & 0.079 & 0.050 & $\begin{array}{l}0.255 \\
(0.000)\end{array}$ & $\begin{array}{l}0.186 \\
(-0.001)\end{array}$ & $\begin{array}{l}0.123 \\
(0.000)\end{array}$ & $\begin{array}{l}0.079 \\
(0.000)\end{array}$ & $\begin{array}{l}0.050 \\
(0.000)\end{array}$ \\
\hline & $\mathrm{N}$ & 0.162 & 0.118 & 0.072 & 0.040 & 0.025 & $\begin{array}{l}0.162 \\
(0.000) \\
\end{array}$ & $\begin{array}{l}0.118 \\
(0.000) \\
\end{array}$ & $\begin{array}{l}0.072 \\
(0.000) \\
\end{array}$ & $\begin{array}{l}0.040 \\
(0.000) \\
\end{array}$ & $\begin{array}{l}0.025 \\
(0.000) \\
\end{array}$ \\
\hline & $\mathrm{E}$ & 0.164 & 0.122 & 0.084 & 0.060 & 0.040 & $\begin{array}{l}0.164 \\
(0.000)\end{array}$ & $\begin{array}{l}0.121 \\
(-0.001)\end{array}$ & $\begin{array}{l}0.084 \\
(0.000)\end{array}$ & $\begin{array}{l}0.059 \\
(-0.001)\end{array}$ & $\begin{array}{l}0.040 \\
(0.000)\end{array}$ \\
\hline & Vert. & 0.455 & 0.408 & 0.295 & 0.152 & 0.075 & $\begin{array}{l}0.397 \\
(-0.058) \\
\end{array}$ & $\begin{array}{l}0.370 \\
(-0.038) \\
\end{array}$ & $\begin{array}{l}0.282 \\
(-0.013) \\
\end{array}$ & $\begin{array}{l}0.153 \\
(+0.001) \\
\end{array}$ & $\begin{array}{l}0.074 \\
(+0.001)\end{array}$ \\
\hline
\end{tabular}




\begin{tabular}{|l|l|l|l|l|l|l|l|l|l|l|l|}
\hline $\begin{array}{l}\text { TOW2 } \\
\text { Mean } \\
\text { RMSE } \\
(\mathrm{m})\end{array}$ & 2D & 0.250 & 0.187 & 0.126 & 0.076 & 0.051 & $\begin{array}{l}0.249 \\
(-0.001)\end{array}$ & $\begin{array}{l}0.186 \\
(-0.001)\end{array}$ & $\begin{array}{l}0.125 \\
(-0.001)\end{array}$ & $\begin{array}{l}0.075 \\
(-0.001)\end{array}$ & $\begin{array}{l}0.051 \\
(0.000)\end{array}$ \\
\cline { 2 - 10 } & $\mathrm{N}$ & 0.131 & 0.099 & 0.062 & 0.034 & 0.023 & $\begin{array}{l}0.131 \\
(0.000)\end{array}$ & $\begin{array}{l}0.099 \\
(0.000)\end{array}$ & $\begin{array}{l}0.061 \\
(-0.001)\end{array}$ & $\begin{array}{l}0.034 \\
(0.000)\end{array}$ & $\begin{array}{l}0.023 \\
(0.000)\end{array}$ \\
\cline { 2 - 10 } & $\mathrm{E}$ & 0.182 & 0.140 & 0.097 & 0.060 & 0.042 & $\begin{array}{l}0.182 \\
(0.000)\end{array}$ & $\begin{array}{l}0.139 \\
(-0.001)\end{array}$ & $\begin{array}{l}0.097 \\
(0.000)\end{array}$ & $\begin{array}{l}0.061 \\
(-0.001)\end{array}$ & $\begin{array}{l}0.042 \\
(0.000)\end{array}$ \\
\cline { 2 - 9 } & Vert. & 0.496 & 0.368 & 0.247 & 0.128 & 0.067 & $\begin{array}{l}0.460 \\
(-0.036)\end{array}$ & $\begin{array}{l}0.345 \\
(-0.023)\end{array}$ & $\begin{array}{l}0.232 \\
(-0.015)\end{array}$ & $\begin{array}{l}0.131 \\
(+0.003)\end{array}$ & $\begin{array}{l}0.068 \\
(+0.001)\end{array}$ \\
\hline
\end{tabular}

\section{Conclusions}

This paper firstly compared the tropospheric models obtained from 1) GPT2, 2) GPT2w, 3) ECMWF gridded data, and 4) BoM GRIB2. An inter-comparison of these models with the IGS ZTD product used as a reference showed that the precision of the ZTD from actual NWM datasets (BoM and ECMWF) were consistently better than the empirical models (GPT2 and GPT2w). The GPT2w model was more precise and accurate than its predecessor GPT2. The ZTD from ECMWF model at IGS station ALIC gave a mean error $=0.007 \mathrm{~m}$ and $\mathrm{std}=0.018 \mathrm{~m}$, and station HOB2 gave mean $=0.006 \mathrm{~m}$ and $\mathrm{std}=0.026 \mathrm{~m}$. However, results were poor at stations TOW2 and YAR2, which is likely to be due to the low resolution of DEM heights used in this model. The ZTD from BoM NWM data gave the best precision and accuracy at all four sites, with mean errors between $-0.034 \mathrm{~m}$ to $0.029 \mathrm{~m}$ and standard deviations better than $0.045 \mathrm{~m}$.

The BoM NWM data was used to constraint the tropospheric delay in PPP processing at the four sites with 5 days data with hourly PPP solutions. The performance of PPP convergence time and achievable accuracy with the BoM NWM constrained troposphere was compared to the traditional case where the troposphere is estimated as an unknown parameter. Improvements in vertical positioning accuracy was found at all the four sites during the first few minutes of initialisation. The BoM constrained troposphere model PPP had better vertical accuracy by $0.036-0.058 \mathrm{~m}$ after 2 minutes, $0.023-0.038 \mathrm{~m}$ after 3 minutes and $0.013-0.020 \mathrm{~m}$ after 5 minutes of PPP initialisation. This result suggests that constraining the troposphere with the BoM NWM data in PPP has some merit in improving the vertical convergence during the first few minutes of initialisation and is beneficial for applications where fast vertical convergence is required. This could be a cost-effective means of improving the PPP vertical convergence using existing NWM data, rather than the more expensive approach of using precise troposphere corrections provided by an external provider using a local GNSS network.

\section{Acknowledgement}

The BoM GRIB2 data was supplied courtesy of Airservices Australia. The IGS (Dow et al., 2009) is acknowledged for provision of the precise orbit and clock products to enable simulation of RINEX data. The precise station coordinates were obtained from the weekly Asia Pacific Reference Frame (APREF) solution provided by Geoscience Australia.

\section{References}

Andrei CO and Chen R. 2009. Assessment of time-series of troposphere zenith delays derived from the Global Data Assimilation System numerical weather model, GPS Solutions, 13: 109-117, doi 10.1007/s10291-008-0104-1.

Askne $\mathbf{J}$ and Nordius H. 1987. Estimation of tropospheric delay for microwaves from surface weather data, Radio Science, 22(3): 379-386.

Böhm J, Heinkelmann R and Schuh H. 2007. Short Note: A Global Model of Pressure and Temperature for Geodetic Applications, Journal of Geodesy, 81(10): 679-683, doi:10.1007/s00190-007-0135-3. 
Böhm J, Möller G, Schindelegger M, Pain G and Weber R. 2015. Development of an improved empirical model for slant delays in the troposphere (GPT2w). GPS Solutions, 19: 433-441, doi 10.1007/s1029-014-0403-7.

Böhm J, Niell AE, Tregoning P and Schuh H. 2006b. Global mapping function (GMF): a new empirical mapping function based on data from numerical weather model data. Geophysical Research Letters 33(L07304), doi 10.1029/2005GL025546.

Böhm J, Werl, B and Schuh H. 2006a. Troposphere mapping functions for GPS and VLBI from ECMWF operational analysis data, Journal of Geophysical Research, 111(B02406), doi 10.1029/2005JB003629.

Collins P, Langley RB, LaMance J. 1996. Limiting factors in tropospheric propagation delay error modelling for GPS airborne navigation. In: Proceedings ION-AM-1996, Institute of Navigation, Cambridge, Massachusetts, June 19-21, pp 519-528

Davis JL, Herring TA, Shapiro II, Rogers AEE and Elgered G. 1985. Geodesy by radio interferometry: effects of atmospheric modelling errors on estimates of baseline length. Radio Science, 20(6): 1593-1607.

Deo M and El-Mowafy A. 2016. Triple-frequency GNSS models for PPP with float ambiguity estimation: performance comparison using GPS. Survey Review. Published online, http://dx.doi.org/10.1080/00396265.2016.1263179.

Dow J, Neilan R and Rizos C. 2009. The International GNSS Service in a changing landscape of Global Navigation Satellite Systems, Journal of Geodesy, 83(3-4): 191-198.

El-Mowafy A. 2015. Estimation of Multi-Constellation GNSS Observation Stochastic Properties Using a Single-Receiver Single-Satellite Data Validation Method. Survey Review, 47(341), 99-108.

El-Mowafy A, Deo M and Rizos C. 2016. On Biases in Precise Point Positioning with MultiConstellation and Multi-Frequency GNSS Data. Measurement Science and Technology, 27(3), 035102.

El-Mowafy A and Lo J. 2014. Dynamic modelling of GNSS troposphere wet delay for estimation of precipitable water vapour. Journal of Applied Geodesy, 8(1), 31-42.

IERS Conventions, Petit G and Luzum B (eds.). 2010. IERS Technical Note 36, Frankfurt am Main: Verlag des Bundesamts für Kartographie und Geodäsie, 179 pp, ISBN 389888-989-6.

Kjørsvik, NS, Gjevestad JGO and Øvstedal O. 2006. Handling of the Tropospheric Delay in Kinematic Precise Point Positioning, Proceedings of the 19th International Technical Meeting of the Satellite Division of the Institute of Navigation (ION GNSS 2006), Fort Worth, TX, September 2006, pp. 2279-2281.

Kouba J. 2009. Testing of global pressure/temperature (GPT) model and global mapping function (GMF) in GPS analyses, Journal of Geodesy, 83: 199-208.

Krueger E, Schüler T, Hein GW, Martelucci A and Blarzino G. 2004. Galileo tropospheric correction approaches developed within GSTB-V1. In: Proceedings of ENC-GNSS 2004, Rotterdam, The Netherlands, May 16-19.

Lagler K, Schindelegger M, Böhm J, Krásná H and Nilsson T. 2013. GPT2: Empirical slant delay model for radio space geodetic techniques, Geophysical Research Letters, 40: 1069-1073.

Laurichesse D and Privat A. 2015. An Open-source PPP Client Implementation for the CNES PPP-WIZARD Demonstrator, ION GNSS 2015, September 15-18, 2015 - Tampa, Florida.

Li T, Wang J, Laurichesse D. 2014. Modeling and quality control for reliable precise point positioning integer ambiguity resolution with GNSS modernization, GPS Solutions, 18(3): 429-442. 
Li W, Yuan Y, Ou J, Li H and Li A. 2012. A new global zenith tropospheric delay model IGGtrop for GNSS applications. Chinese Science Bulletin: 57(17): 2132-2139.

Li X, Jiang R, Song X, Li B. 2017. A Tightly Coupled Positioning Solution for Land Vehicles in Urban Canyons. Journal of Sensors, 2017 (Article ID 5965716), https://doi.org/10.1155/2017/5965716.

Lu C, Chen X, Liu G, Dick G, Wickert J, Jiang X, Zheng K and Schuh H. 2017. Real-Time Tropospheric Delays Retrieved from Multi-GNSS Observations and IGS Real-Time Product Streams. Remote Sensing, 9(12), 1317; doi:10.3390/rs9121317.

Lu C, Zus F, Ge M, Heinkelmann R, Dick G, Wickert J and Schuh H. 2016. Tropospheric delay parameters from numerical weather models for multi-GNSS precise positioning. Atmospheric Measurement Techniques, 9: 5965-5973, Atmos. Meas. Tech., 9, 59655973, https://doi.org/10.5194/amt-9-5965-2016.

Martellucci A. 2012. Galileo reference troposphere model for the user receiver. ESAAPPNG-REF/00621-AM v2.7.

Neill AE. 1996. Global Mapping Functions for the Atmosphere Delay at Radio Wavelengths. Journal of Geophysical Research, 101(B2):3227-3246.

Saastamoinen J. 1972. Atmospheric correction for the troposphere and stratosphere in radio ranging satellites. Geophysical Monograph, Henriksen (ed), 15: 247 - 251.

Saastamoinen J. 1973. Contributions to the theory of atmospheric refraction, Bullétin Géodésique. 107(1): 13-34. Part 3 of 3.

Schüler T. 2014. The TropGrid2 standard tropospheric correction model. GPS Solutions 18(1):123-131.

Shi J, Xu C, Guo J and Gao Y. 2014. Local troposphere augmentation for real-time precise point positioning. Earth, Planets and Space 66(30): 1-13, doi:10.1186/1880-5981-6630.

Steigenberger P, Böhm J and Tesmer V. 2009. Comparison of GMF/GPT with VMF1/ECMWF and Implications for Atmospheric Loading. Journal of Geodesy, 83(10): 943-951, DOI: 10.1007/s00190-009-0311-8.

Talbot N, Chen X, Reussner N, Brandl M, Nitschke M, Rodriguez-Solano C and Zhang F. 2015. Trimble RTX Orbit Determination and User Positioning Performance with BeiDou Satellites, IGNSS Conference, 6-8 December 2016, UNSW Australia.

Tuka A, El-Mowafy A. 2013. Performance Evaluation of Different Troposphere Delay Models and Mapping Functions, Measurement 46(2): 928-937, DOI: 10.1016/j.measurement.2012.10.015.

Vaclavovic P, Dousa J, Elias M and Kostelecky J. 2017. Using external tropospheric corrections to improve GNSS positioning of hot-air balloon. GPS Solutions 21: 1479, https://doi.org/10.1007/s10291-017-0628-3

Yue X, Schreiner WS, Lei J, Sokolovskiy SV, Rocken C, Hunt DC, and Kuo YH. 2010: Error analysis of Abel retrieved electron density profiles from radio occultation measurements. Annales Geophysicae, 28: 217-222, doi:10.5194/angeo-28-217-2010.

Zhang H, Yuan Y, Li W and Chai Y. 2016. Assessment of Three Tropospheric Delay Models (IGGtrop, EGNOS and UNB3m) Based on Precise Point Positioning in the Chinese Region, Sensors, 16(122): 1-12, doi:10.3390/s16010122.

Zheng F, Lou Y, Gu S, Gong A and Shi C. 2017. Modeling tropospheric wet delays with national GNSS reference network in China for BeiDou precise point positioning. Journal of Geodesy, published online 29 Oct 2017, pp 1-16, doi: https://doi.org/10.1007/s00190-017-1080-4.

Zhou C, Peng B, Li W, Zhong S, Ou J, Chen R and Zhao X. 2017. Establishment of a SiteSpecific Tropospheric Model Based on Ground Meteorological Parameters over the China Region. Sensors, 17(8), 1722; doi:10.3390/s17081722. 